\title{
Fragility reduction of offshore wind turbines using tuned liquid column dampers
}

6

\author{
Arash Hemmati ${ }^{\mathrm{a}}$, Erkan Oterkus ${ }^{\mathrm{a}, 1}$, Nigel Barltrop ${ }^{\mathrm{b}}$

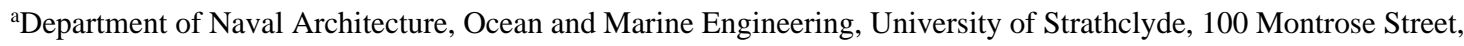 \\ Glasgow G4 OLZ, UK
}

\begin{abstract}
:
High flexibility of offshore wind turbines (OWTs) makes them vulnerable to excessive vibrations. This paper studies vibration control of offshore wind turbines induced by multi-hazard excitations. A model consisting of entire offshore wind turbine foundation and tower controlled by tuned liquid column dampers (TLCD) considering nonlinear soil pile interaction is established. The model is subjected to wave, wind, and seismic loading. The effect of severity of earthquake on the performance of the structural control device is investigated. A fragility analysis based on acceleration capacity thresholds is performed to estimate reliability improvement using the structural control devices. The fitted fragility functions based on multiple stripes analysis are constructed and compared with the empirical cumulative distribution curves. The results suggest that the use of an optimal TLCD with a mass ratio of $2.5 \%$ reduces the fragility of the system by as much as $6 \%$ and $12 \%$ for operational and parked conditions, respectively.
\end{abstract}

Keywords: Offshore wind turbine, fragility analysis, vibration control, tuned liquid column damper

\section{INTRODUCTION}

With a constantly increasing demand for energy and a higher level of public environmental concerns over conventional energy sources, wind energy has become the key part of renewable energy. Offshore wind energy is also becoming more popular due to steady and high wind speed, and less visual impact. However, offshore wind turbines are subjected to highly dynamic loading including wind, wave, current, and excitations due to frequency of turbine itself in conjunction with seismic loading in places vulnerable to earthquake events such as New Zealand, Japan, China, and USA. High flexibility and slenderness of offshore wind turbine foundations, especially monopiles, induced by the mentioned simultaneous loadings result in excessive vibrations and consequently high fatigue damage and serviceability issues. Therefore, these excessive vibrations need to be minimized to ensure the safety of these structures during their foreseen lifetime (20-25 years).

One practical approach is to utilize structural control devices developed in the civil engineering field. Three main structural control systems such as active, passive, and semi-active have been used for a number of structures [1]. Passive control systems can minimize vibrations without employing force devices, complex sensors, and instrumental equipment. There are various damping devices such as tuned mass dampers, tuned liquid dampers, and fluid dampers. Tuned mass dampers (TMDs) have been implemented in tall buildings, towers and bridges and its effectiveness during earthquake ground motions has been well proved. Due to the simplicity of TMDs, they

\footnotetext{
${ }^{1}$ Corresponding author:

E-mail address: erkan.oterkus@strath.ac.uk
} 
have been popular in the wind industry and there have been a number of studies focusing on wind turbine tower using TMD [2-6]. Stewart and Lackner [4] examined the impact of passive tuned mass dampers considering windwave misalignment on offshore wind turbine loads for monopile foundation. The results demonstrated that TMDs are effective in damage reduction of towers, especially in side-side directions. Stewart and Lackner [5] in another study investigated the effectiveness of TMD systems for four different types of platforms including monopile, barge, spar buoy, and tension-leg and they observed tower fatigue damage reductions of up to $20 \%$ for various TMD configurations. There have also been some investigations on the impact of TMDs on wind turbine blades [7-9]. Fitzgerald and Basu [7] studied the use of active tuned mass dampers to control in-plane vibrations of wind turbine blades and demonstrated promising results, especially for high turbulent loadings. Multiple tuned mass dampers (MTMD) was proposed to improve the effectiveness of vibration control system [10]. Dinh and Basu [10] investigated the use of MTMDs for structural control of nacelle and tower of spar floating wind turbines and concluded that MTMDs are more effective in displacement reductions. Haoran et al. [11] proposed MTMDs to control excessive vibrations excited by higher modes of offshore wind turbine tower under multi-hazard and concluded that installing the control devices along the tower improves the performance of the system. More recently, Sun [12] investigated implementation of semi-active TMDs for mitigating dynamic response of an offshore wind turbine considering damage development due to earthquake motions. Cao and $\mathrm{Li}$ [13] proposed an integrated system as tuned tandem mass dampers-inerters (TTMDI) for reducing structural excitations and compared with the multiple tuned mass dampers. They concluded that this system is superior due to its broadband characteristics. $\mathrm{Li}$ and $\mathrm{Qu}$ [14] studied the application of multiple tuned mass dampers (MTMDs) for mitigating both translational and torsional responses of the structures subject to ground motions. They demonstrated the robustness of MTMDs for the case of torsional response of asymmetric structures. Jangid [15] investigated the performance of multiple tuned mass dampers (MTMD) in reducing dynamic response of structures under base excitations in a parametric study and he concluded that MTMD systems can be a more robust than a single TMD with similar properties. Jangid [16] proposed optimum parameters of multiple tuned mass dampers (MTMDs) for undamped systems under base excitations. Jangir [16] used a numerical searching technique to find explicit formula which can be used for design purposes.

Tuned Liquid Column Dampers (TLCDs) are another popular vibration control system that has been used in civil engineering due to its easier maintenance requirements and lower costs. They have been used to mitigate windinduced motion of high rise buildings [17]. The effectiveness of TLCDs in structural control of wind energy has been studied by a number of researchers [18-22]. Ghaemmaghami et al. [18] concluded that tuned liquid dampers are effective for small amplitude excitations. Cowell and Basu [19] studied effects of TLCD on offshore wind turbine systems to suppress the excessive vibrations and found that TLCD can minimize vibrations up to $55 \%$ of peak responses of OWTs compared to the uncontrolled system. There have also been studies on the effectiveness of TLCD on vibration suppression of wind turbine blades that achieved improved results [20, 21]. Mensah and Dueñas-Osorio [22] investigated reliability improvement of an onshore wind turbine equipped with TLCDs under only wind-induced excitations and their results show a considerable reduction in displacement and bending moment in the tower. Although their findings are comprehensive, their work is limited to onshore wind turbines and a study focusing on reliability improvements of offshore wind turbines offered by structural control devices is needed as offshore wind turbines face larger environmental loadings and consequently lower reliability levels. Furthermore, their work is limited to reliability analysis for only wind and wave loading for places located with low risk of earthquake events in which the seismic loading can be ignored in the reliability analysis. However, more wind turbines are being installed in earthquake-prone places and including seismic excitations in the structural analysis of wind turbines is becoming more necessary. Matteo et al [23] proposed a model for tuned liquid column dampers (TLCDs) based on fractional formulation in time and frequency domains which was validated by experiments. Matteo et al [24] formulated optimal TLCD parameters using the numerical Monte Carlo simulation for design purposes. Coudurier et al [25] studied application of tuned liquid multi-column dampers for floating wind turbines and proved that that these devices are robust for floating wind turbines in the event of wave incidents. Buckley et al [26]investigated the potential of a Tuned Liquid Column Damper (TLCD) to mitigate excessive vibrations of a wind turbine tower with different soil pile interaction properties. They used scaled laboratory experiments to validate the model and then investigated the performance of these devices under various loading conditions. 
Due to the fact that the wind farms developed in the last two decades were located in the places where earthquake events rarely occur, few studies considering seismic loading have been performed. Prowell et al. [27, 28] and Zhao et al. $[29,30]$ studied the behavior of onshore wind turbines under seismic excitations using nonlinear time domain simulations based on multi-body dynamic formulations. Prowell et al. [27, 28] claimed that seismic bending moment demand at the base of the tower is considerably above the demand from other extreme events such as extreme wind under various operational and non-operational conditions and the seismic design consideration may be a design driving factor for large wind turbines. Zhao et al. [29, 30] concluded that force and bending moment at the base of the structure are highly affected by even weak seismic excitations especially in the side-side direction where aerodynamic loading is lacking.

There have been two main approaches regarding seismic hazards in wind turbines: deterministic and probabilistic. Bazeos et al. [31] performed both deterministic and probabilistic analyses for wind turbines subjected to seismic loading and observed similar results for two analysis methods. Witcher [32] conducted time domain simulation for wind turbines considering full aeroelasticity of GH Bladed wind turbine simulation package. Song et al. [33] concluded that the inclusion of the earthquake ground motions for the reliability of a wind turbine is necessary. In addition, Alati et al. [34] investigated the impact of seismic motion on tripod and jacket foundations for offshore wind turbines considering operational conditions. They confirmed the fact that the seismic design load is the dominating design driver. Jin et al. [35] studied the seismic behavior of wind turbines using an integrated multibody system and concluded that the power production is threatened even for the case of inflicted structural detriment. With regard to the probabilistic approach for seismic loading, fewer studies can be found. Nuta et al. [36] conducted a research on probabilistic assessment of seismic induced wind turbines using an incremental dynamic analysis procedure (IDA) and generated probabilistic estimations for various Damage Stages (DS). Furthermore, Mardfekri and Gardoni [37] developed a probabilistic model under the multi-hazard condition of offshore wind turbine and analyzed the reliability of the wind turbines. This study covered a wide range of structural characteristics for the operational wind turbine using the annual occurrence probability of the hazards and claimed that actual probability of failure is higher than target safety recommended by standards. Kim et al. [38] investigated the responses of the NREL 5MW wind turbine on a monopile under real and artificial seismic excitation using a simplified lumped mass model including nonlinear springs representing soil-pile interaction. They proposed that the fragility curves for various peak ground accelerations (PGAs) can be constructed by static pushover analysis. The fragility analyses performed in the previous studies were mostly based on conventional methods. Baker [39] investigated the effectiveness of various methods for fragility analysis under seismic loading based on drift threshold for general structures and showed that multiple stripe analysis produces more efficient fragility functions compared to other conventional methods. However, the applicability of this method for offshore wind turbines under multi-hazard condition should be investigated.

To fill aforementioned gaps, the present study investigates the structural control of the offshore wind turbines under multi-hazard conditions considering nonlinear soil pile interaction and a fragility analysis is performed for the model and reliability improvement is discussed. Tuned liquid column dampers are considered as the structural control device in this study because it can be installed not only in the nacelle but also in various elevations of the tower and also it requires a lower level of maintenance. The novelty of this study can be explained in two parts. On one hand, the structural dynamic responses such as displacement and base forces are investigated for the offshore wind turbine modeled as multi-degrees of freedom considering nonlinear soil pile interaction and equipped with the optimal structural control device. Wind, wave, seismic and gravity loadings are incorporated into the model. On the other hand, a fragility analysis based on the acceleration threshold is constructed for the controlled and uncontrolled systems in order to estimate the reliability improvement offered by the structural control devices. To perform a more robust fragility analysis, an optimized method of fragility analysis named multiple striped analysis is used that has not been utilized for offshore wind turbine systems.

This paper is organized into five sections. In section 2, the numerical model of the system including tuned liquid column dampers, the wind turbine, and soil pile interaction is presented. Section 3 defines the excitation sources including wind, wave, and earthquake. The numerical results and discussions are presented in section 4 and conclusions are made in section 5 . 


\section{NUMERICAL MODEL}

The equation of motion of a three-dimensional monopile wind turbine model equipped with TLCDs is established and solved using nonlinear Newmark method [40]. Details of the equation of the motion, wind turbine model, and soil-pile interaction are presented in the following sections.

\subsection{Tuned Liquid Column Dampers}

TLCDs are composed of a U-shaped tube that is partially filled with liquid and dissipate vibration energy using the oscillation of the liquid between two columns. This oscillation of the liquid enables the system to re-establish equilibrium and dampen out the vibration. Fig. 1 shows a schematic configuration of a TLCD attached to the main structure.

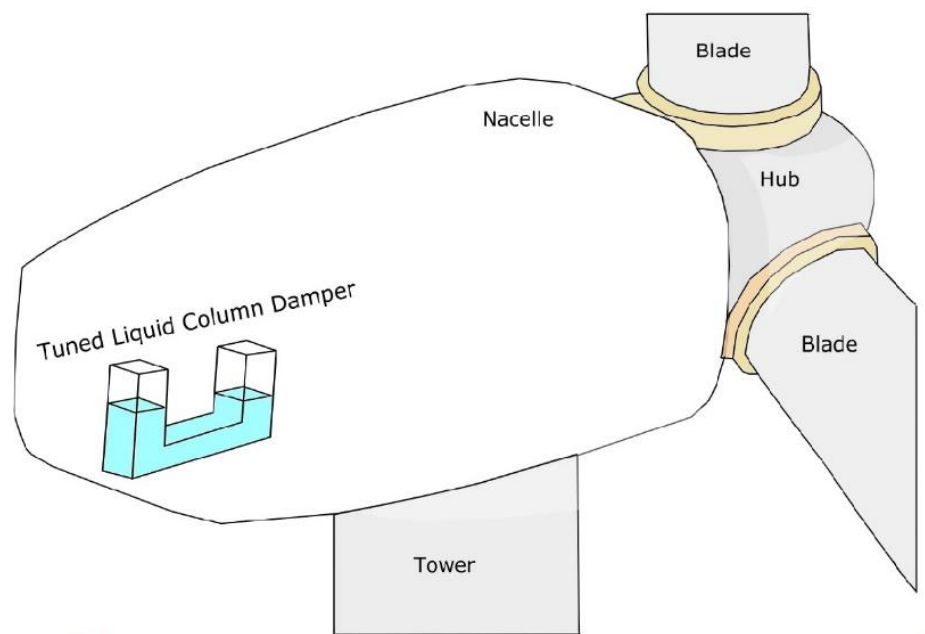

(a)

(b)

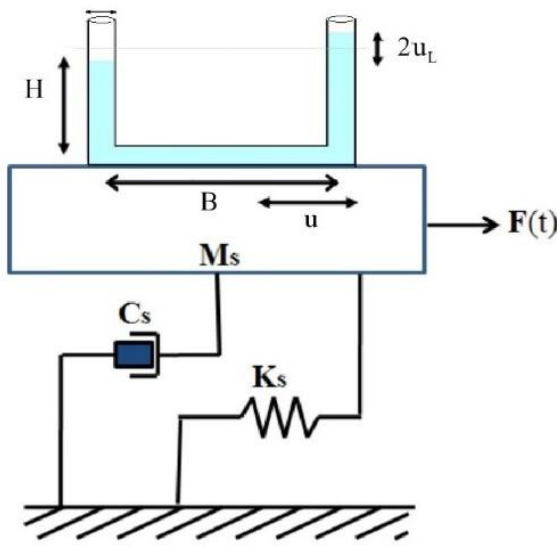

Fig. 1. Schematic diagram (a) turbine (b) tuned liquid column damper

Two major assumptions are used to derive dynamic equations of TLCDs: (1) the liquid is incompressible and no pressure is created due to the oscillation of the liquid in the tube, (2) the sloshing of the liquid surface may be ignored as it is negligible compared to the sloshing of the whole body of water. The equation of motion of a Ushaped pipe attached to a structure for controlling vibrations of the structure was developed by [17] and can be described as:

$\rho A_{d} L_{T} \ddot{u}_{L}+\frac{1}{2} \rho A \xi\left|\dot{u}_{L}\right| \dot{u}_{L}+2 \rho A g u_{L}=-\rho A B \ddot{u}$

where $\rho$ is the density of the fluid, $A_{d}$ is the cross-sectional area of the tube, $B$ is the horizontal distance between two columns, $g$ is the acceleration due to gravity, $u_{L}$ is the change in the elevation of the liquid inside the columns and $u$ is the horizontal deflection at the base of TLCD where it is attached to the OWT systems that can be located in nacelle, tower or transition piece. The overdot denotes differentiation with respect to time. $\xi$ is the non-linear coefficient of head loss which is dependent on the opening ratio of the orifice $\psi$ (ratio of the diameter of the orifice to the diameter of the horizontal tube). $\xi$ can be calculated from the empirical formula developed from experimental results [41]:

$\xi=\left(-0.6 \psi+2.1 \psi^{0.1}\right)^{1.6}(1-\psi)^{-2}$

Eq. (1) can be rewritten by dividing with the mass of the liquid as

$\ddot{u}_{L}+\frac{\xi}{2 L}\left|\dot{u}_{L}\right| \dot{u}_{L}+\omega_{L}^{2} u=-\alpha \ddot{u}$

in which $L_{T}=B+2 H$ is the total length of the tube, $\alpha=B / L_{T}$ is the ratio of horizontal length to the total length, $\omega_{L}=\sqrt{2 g / L_{T}}$ is the natural circular frequency of the TLCD. 
1 The equation of motion of the main structure with n-degrees of freedom attached to the TLCD can be expressed as:

$$
M_{s} \ddot{X}+C_{s} \dot{X}+K_{s} X=P(t)-\rho A B \ddot{u}_{L} R-\rho A L_{T} \ddot{u} R
$$

in which $X=\left\{x_{1}, x_{2}, \ldots, x_{n}\right\}^{\mathrm{T}}$ is the horizontal displacement vector of the main structure, and $R=\{1,0, \ldots, 0\}^{\mathrm{T}}$ is a constant vector. $K_{s}, M_{s}$, and $C_{s}$ are the n-dimensional stiffness, mass, and damping matrices of the main structure, respectively. $P(t)$ is an n-dimensional vector of external force applied to the main structure.

9 The tuned liquid column damper is tuned to the first natural frequency of the system by tuning ratio $\gamma=\omega_{L} / \omega_{s}$ which is controlled by the mass ratio $\mu=m_{T L C D} / m_{s} . \omega_{L}$ and $\omega_{s}$ are the system frequency of the TLCD and natural frequency of the main structure, respectively. $m_{T L C D}$ and $m_{s}$ are the mass of TLCD and the mass of the main structure, respectively.

The arrangement of the baseline TLCD for this study is a TLCD with a mass ratio of $2.5 \%$ located in the nacelle. The type of the liquid is selected as water, resulting in a need for $22.675 \mathrm{~m}^{3}$ space. This required volume can be reduced by using other liquids such as glucose solution with a density of $1540 \mathrm{~kg} / \mathrm{m}^{3}$, resulting in $35 \%$ saving in the required space. However, it should be noted that use of high density liquid could lead to lower control performances. Another option to increase the effectiveness of TLCD is to increase the dimension of the cross section of columns, however it could lead to sloshing and also there are space limitations in offshore wind turbines. Alternatively, using multiple tuned liquid column dampers in nacelle and tower can be another practical solution. Here one single TLCD is assumed to be installed in the nacelle. The optimal tuning ratio is set as $\gamma=1 /(1+\mu)$ and other parameters are tabulated in Table 1. Horizontal length and length ratio are chosen based on practical considerations and space limitations in the nacelle (less than $6 \mathrm{~m}$ ). The optimal headloss is found by changing headloss values in an optimization loop and finding the minimal dynamic responses.

\begin{tabular}{lclc}
\multicolumn{4}{l}{ Table 1 TLCD parameters } \\
\hline Mass ratio $(\mu)$ & $2.5 \%$ & Total length $(L)$ & $9.89 \mathrm{~m}$ \\
Frequency ratio $(\gamma)$ & $97.5 \%$ & Horizontal length $(B)$ & $5.93 \mathrm{~m}$ \\
Length ratio $(\alpha)$ & 0.6 & Headloss coefficient $(\xi)$ & 30 \\
\hline
\end{tabular}

\subsection{NREL 5MW Wind Turbine}

In this study, NREL 5 MW wind turbine was considered as it is widely used as the turbine for benchmark studies [42]. This turbine is supported by baseline monopile foundation developed in the second phase of Offshore Code Comparison (OC3) project [43] conducted by NREL. The total length of the monopile is $66 \mathrm{~m}$, in which $10 \mathrm{~m}, 20$ $\mathrm{m}$, and $36 \mathrm{~m}$ are above the mean sea level, in the water and under the seabed, respectively. The general configuration of the turbine is shown in Fig. 2. The total offshore wind turbine system is modeled by threedimensional Timoshenko beam theory. 


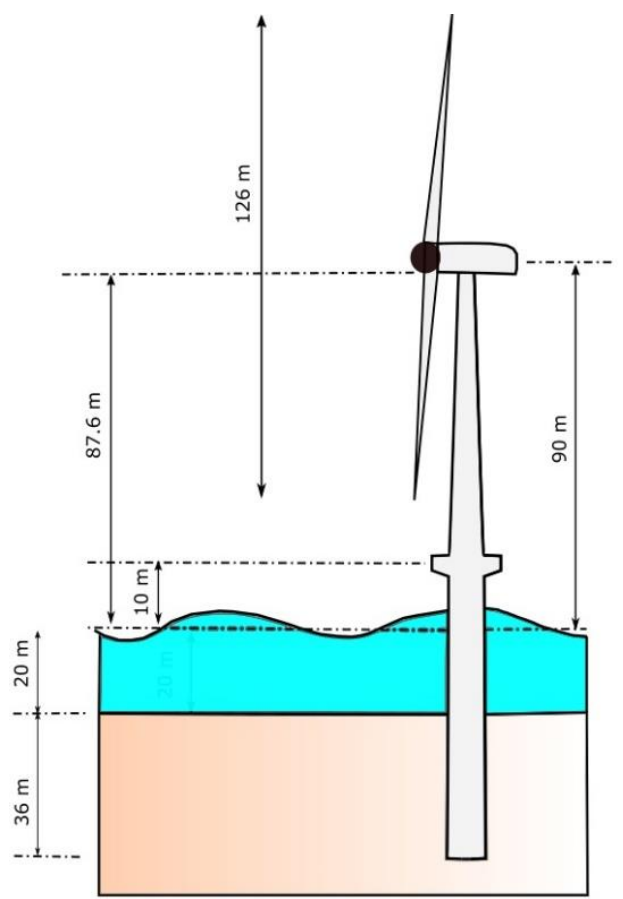

Fig. 2. Schematic configuration of the offshore wind turbine

3

4 The particulars of the offshore wind turbine can be found in Table 2. Table 3 tabulates the material properties of 5 the steel used in the tower and monopile of the offshore wind turbine. The density of the steel in the tower is taken 6 higher than that of the regular steel to take into account the weight of the paint, bolts, welds, and flanges which 7 are not modeled directly [44].

8

Table 2 Properties of NREL 5MW baseline turbine

\begin{tabular}{lllr}
\hline Turbine & Rated power, Rotor Orientation & 5MW, UpWind, 3 Blades & 10 \\
& Control System & Variable Speed, Collective Piq̣ \\
Blade & Rotor Diameter, Hub Height & $126 \mathrm{~m}, 90 \mathrm{~m}$ & 12 \\
& Cut-In, Rated, Cut-Out Wind Speed & $3 \mathrm{~m} / \mathrm{s}, 11.4 \mathrm{~m} / \mathrm{s}, 25 \mathrm{~m} / \mathrm{s}$ & 13 \\
& Cut-In, Rated Rotor Speed & $6.9 \mathrm{rpm}, 12.1 \mathrm{rpm}$ & \\
\multirow{5}{*}{ Nacelle } & Hub mass, Blade mass & $56,780 \mathrm{~kg}, 17,740 \mathrm{~kg}$ & 14 \\
& Nacelle Dimensions & $18 \mathrm{~m} * 6 \mathrm{~m} * 6 \mathrm{~m}$ & 15 \\
Tower & Nacelle Mass & $240,000 \mathrm{~kg}$ & \\
& Base diameter, base thickness & $6.0 \mathrm{~m}, 27 \mathrm{~mm}$ & 16 \\
& Top diameter, top thickness & $3.87 \mathrm{~m}, 19 \mathrm{~mm}$ & 17 \\
\hline
\end{tabular}

18

Table 3 Material Properties

\begin{tabular}{lllll}
\hline Component & Density $\left(\mathrm{kg} / \mathrm{m}^{\wedge} 3\right)$ & Young's modulus $(\mathrm{GPa})$ & \multicolumn{2}{l}{ Poisson’s ra20 } \\
\hline Tower & 8500 & 210 & 0.3 & 21 \\
Monopile & 7850 & 210 & 0.3 & 22 \\
\hline
\end{tabular}

\subsection{Soil-Pile Interaction}

The non-linear soil resistance-deflection relationship for sand layers can be defined as [45]:

29 
1 where $A$ is a constant and equal to 0.9 for cyclic loading, $y$ is the lateral deflection, and $k$ is the initial modulus

2 of subgrade reaction which is determined from a function of the angle of internal friction, $\phi^{\prime}$, [45]. $H$ is depth

3 and $p_{u}$ is the ultimate lateral bearing capacity determined by the following equation:

$4 \quad p_{u}=\min \left\{\begin{array}{c}p_{u s}=\left(C_{1} H+C_{2} D\right) \gamma H \\ p_{u d}=C_{3} D \gamma H\end{array}\right.$

5 where $D$ is the pile diameter, $\gamma$ is the effective soil weight, and $C_{1}, C_{2}$, and $C_{3}$ are coefficients determined from

6 API standard [45, 46]. Soil layer properties are shown in Fig. 3a. The nonlinear resistance-deflection curves 7 constructed based on the aforementioned method for different soil layers are illustrated in Fig. $3 \mathrm{~b}$.

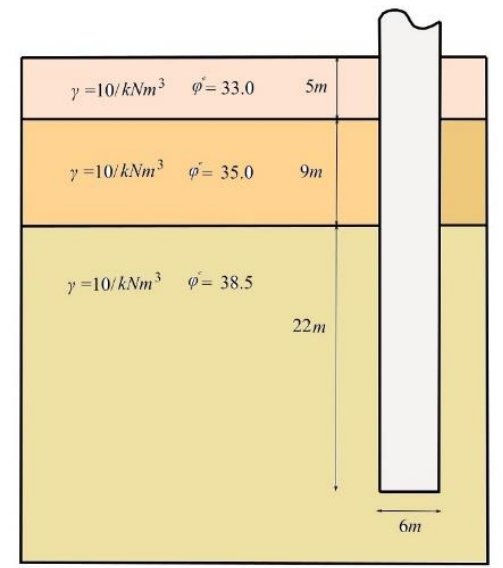

(a)

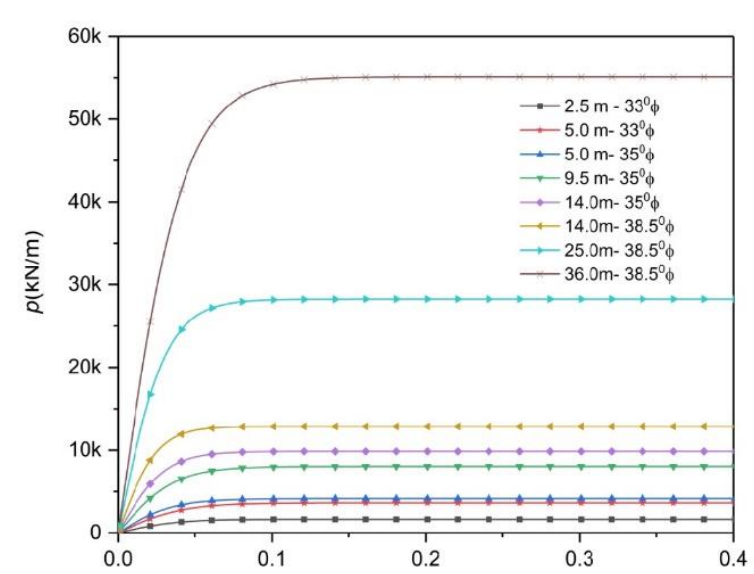

(b)

$y(\mathrm{~m})$

Fig. 3 (a) Soil layer properties (b) nonlinear resistance-deflection curves

\section{LOADING}

This section describes the formulation and properties of wind, wave, and seismic loadings applied to the model.

\subsection{Wind}

The wind speed acting on the system can be represented by a constant mean wind load $\bar{v}$, and a turbulent wind component $\hat{v}(t), v(t)=\bar{v}+\hat{v}(t)$. The mean velocity $\bar{v}(z)$ is calculated using the logarithmic wind profile as:

$\bar{v}(z)=V_{r e f} \frac{\log \left(z / z_{0}\right)}{\log \left(H_{r e f} / z_{0}\right)}$

where $V_{r e f}$ is the mean velocity at the reference height $H_{r e f}=90 m, z$ is the vertical coordinate, and $z_{0}$ is the roughness length.

The Kaimal spectrum [47] is adopted in this study to calculate the turbulent wind velocity and can be expressed as

$S_{v}(f)=\frac{4 I^{2} L_{k}}{\left(1+6 f L_{k} / \bar{v}\right)^{5 / 3}}$

where $I$ is the wind turbulence intensity, $f$ is the frequency $(\mathrm{Hz})$, and $L_{k}$ is the integral scale parameter. 
1 For continuous structures modeled as a multi degrees of freedom system, the power spectrum of fluctuating drag

2 force is represented by the following [48]

$3 \quad S_{f, j}(f)=\left(C_{D} A_{T} \rho\right)^{2} \sum_{k=1}^{N} \sum_{l=1}^{N} S_{v_{k} v_{l}}(f) \bar{v}_{k} \bar{v}_{l} \phi_{j}(k) \phi_{j}(l)$

4 where $C_{D}$ is the drag coefficient; $A_{T}$ is the total surface area of the tower subjected to the wind, $\rho$ is the air density,

$5 \quad k$ and $l$ are spatial nodes, $\bar{v}_{k}$ and $\bar{v}_{l}$ are the mean wind velocities at the mentioned nodes, $\phi_{j}(k)$ and $\phi_{j}(l)$ are

6 the jth mode shape at the nodes, and $S_{v_{t},}(f)$ is the cross power spectral density function of wind velocity

7 between locations $k$ and $l$ which is defined as

$8 \quad S_{v_{k} v_{l}}(f)=\operatorname{Coh}(k, l ; f) \sqrt{S_{v_{k} v_{k}}(f) S_{v_{l} v_{l}}(f)}$

9 in which $S_{v_{k} v_{k}}$ and $S_{v_{l} v_{l}}$ are the wind velocity auto spectra at points $k$ and $l$, respectively, as defined by Eq. (9), 10 and $\operatorname{Coh}(k, l ; f)$ is the spatial coherence function from IEC [49] which is expressed as:

$\operatorname{Coh}(k, l: f)=\exp \left(-a \sqrt{\left(\frac{f l}{\bar{v}_{h u b}}\right)^{2}+\left(\frac{0.12 L}{L_{c}}\right)^{2}}\right)$

in which $a$ is the coherence decrement, $L$ is the distance between points $k$ and $l$ on the grid, $L_{c}$ is coherence scale parameter and $\bar{v}_{h u b}$ is the mean wind speed at the hub. In the present study, the air density, the coherent decrement, the coherence scale parameters, the roughness length, and the drag coefficient are taken as $1200 \mathrm{~kg} / \mathrm{m}^{3}, 12,340.2$ $\mathrm{m}, 0.005$, and 1.2, respectively. In this study, a 3D wind velocity field with 961 points $(31 \times 31)$ which covers the rotors is generated based on Eqs. (9)-(11) using Turbsim code [50]. Next, the generated wind velocity field is used in NREL simulation tool [42] to simulate the time history of wind loading applied to the system. Finally, the generated wind loading time history is used in the developed code to consider aerodynamic loading.

\subsection{Sea Wave Load}

Wave excitation on cylindrical structural members of fixed platforms can be calculated using the Morison equation [51]. The transverse sea wave force acting on a strip of a length $d z$ of a monopile can be expressed as [52]

$d F=\frac{\rho_{w}}{2} C_{d} D v|v| d z+\frac{\pi D^{2}}{2} C_{m} \rho_{w} \dot{v} d z$

where $C_{d}$ and $C_{m}$ are the drag and inertia coefficients, respectively ( $C_{d}=1.2$ and $C_{m}=2$ in the current study), $D$ is the diameter of the member, $\dot{v}$ and $v$ are horizontal acceleration and velocity of fluid particles induced by wave excitations, and $\rho_{w}$ is water density $\left(1025 \mathrm{~kg} / \mathrm{m}^{3}\right)$.

To generate wave time histories, the spectrum developed through Joint North Sea Wave Observation Project (JONSWAP) project is used [53].

$S_{\eta \eta}(f)=\frac{\alpha g^{2}}{f^{5}} \exp \left[-\frac{5}{4}\left(\frac{f_{m}}{f}\right)^{4}\right] \gamma^{\exp \left[-\frac{\left(f-f_{m}\right)^{2}}{2 \sigma^{2} f_{m}^{2}}\right]}$ 
and

$6 \quad \sigma=\left\{\begin{array}{l}0.07 f \leq f_{m} \\ 0.09 f>f_{m}\end{array}\right.$

7 where $U_{10}$ is the mean wind velocity at $10 \mathrm{~m}$ from the sea surface, and $F$ is the fetch length in which the wind blows without any change of direction.

Then total wave force acting on the structural members can be calculated as

$$
F_{f}(t)=\int_{0}^{d} d F \phi_{f}(z) d z
$$

where $d F$ is the wave loading on the member mentioned in Eq. (12), and $\phi_{f}$ is the shape function of the offshore structure subjected to wave loading, $d$ is the depth of the water surface, and $z$ is the vertical direction.

Time series of acceleration of strong ground motions recorded during past earthquake events are used to simulate seismic excitation. Two horizontal directions are selected to represent the behavior of earthquake events. In this study, sloshing of water surrounding the structure is ignored as it is believed to have insignificant effects. The seismic records are selected from PEER NGA Database [54] as it includes thousands of records with various mechanisms, soil types, intensities and durations. The details of the ground motion records used in this study are presented in the Appendix. The magnitudes of the events range from 6.5 to 7.5. The seismic loading is assumed to start at the instant of $100 \mathrm{sec}$.

\section{NUMERICAL RESULTS}

\subsection{Model Verification}

In this section, the developed model in MATLAB is verified by performing natural frequency and dynamic analyses. To perform the natural frequency analysis, the stiffness of nonlinear soil pile interaction is linearized by obtaining initial stiffness of the $p-y$ curves [55]. The resulting first and second natural frequencies are listed in Table 4 and compared with the results of the model constructed by commercial finite element software ANSYS and the results from the literature [38]. There is a good agreement between the results of natural frequency analyses.

\begin{tabular}{lccc}
\multicolumn{4}{l}{ Table 4 Frequency analysis results } \\
\hline Mode & Code & ANSYS & Dong Hywan Kim et al [38] \\
\hline $1^{\text {st }}$ Fore-aft & 0.235 & 0.234 & 0.234 \\
$1^{\text {st }}$ Side-to-side & 0.235 & 0.234 & 0.233 \\
$2^{\text {st }}$ Fore-aft & 1.426 & 1.426 & 1.406
\end{tabular}


Next, the results of the dynamic analysis for the offshore wind turbine subjected to Kobe ground motion is compared with the results obtained from the dynamic analysis performed in ANSYS. Fig. 4a shows the non-scaled time history of acceleration of Kobe earthquake starting from the instant of $100 \mathrm{~s}$. Fig. $4 \mathrm{~b}$ shows the time history of the top tower displacement simulated with the code written in MATLAB and the corresponding results obtained from ANSYS. The good agreement between two responses verifies the dynamic analysis solution used in the code.
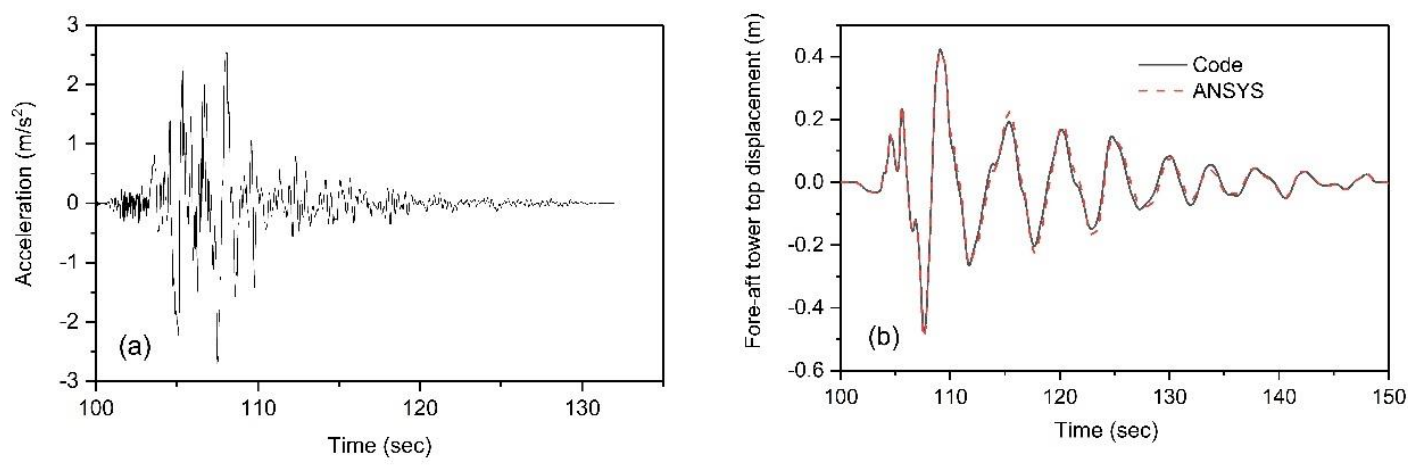

Fig. 4 (a) Time history of acceleration of seismic excitation (Kobe) (b) time history of fore-aft tower top displacement simulated with ANSYS and the developed code under Kobe earthquake

\subsection{Dynamic response of uncontrolled OWTs}

In this section, the responses of the uncontrolled offshore wind turbine structure under multi-hazard conditions are discussed to give a preliminary insight into the dynamic responses. Not to further complicate the problem, the structural control devices are not considered in this section. Two major excitation scenarios are considered. In the first scenario, $\mathrm{LC} 1$, the turbine is operating under wind and wave loadings at the rated wind speed and the seismic event occurs at the instant of $100 \mathrm{~s}$. The rated wind speed is the minimum wind speed at the hub in which the turbine generates the maximum electricity and this wind speed is selected as the most probable operational wind speed according to the probability distribution. In the second scenario, the parked turbine is subjected to higher wind and wave loadings in conjunction with the impact of earthquake excitation which comes in at the instant of $100 \mathrm{~s}$. The detailed environmental parameters are listed in Table 5. The damping ratios used in this study are taken as $5 \%$ and $1 \%$ of critical damping for the operational and parked conditions, respectively, as used in the previous studies $[32,56,57]$.

Table 5 Loading condition information

\begin{tabular}{|c|c|c|c|c|c|}
\hline & \multirow{2}{*}{$\begin{array}{l}\text { Wind loading } \\
\text { Wind speed at the hub height }(\mathrm{m} / \mathrm{s})\end{array}$} & \multicolumn{3}{|c|}{ Wave loading } & \multirow[b]{2}{*}{ Damping } \\
\hline & & Turbulence intensity (\%) & $\begin{array}{l}\text { Wave period } \\
(\mathrm{sec})\end{array}$ & $\begin{array}{l}\text { Significant wave } \\
\text { height }(\mathrm{m})\end{array}$ & \\
\hline LC1 & 11.4 & 14.5 & 9.5 & 5.0 & $1 \%$ \\
\hline
\end{tabular}

Fig. 5 shows the sea elevation time history for the two cases. Fig. 6 illustrates time history of the resultant wave loading acting on the monopile at the mean water level for two load cases. The maximum wave loading for the operational condition with $5 \mathrm{~m}$ significant wave height is $2300 \mathrm{kN}$. The corresponding value for the parked condition is $3900 \mathrm{kN}$ when the significant wave height is $7 \mathrm{~m}$, resulting in $69 \%$ increase in wave loading due to $40 \%$ increase in significant wave height. It is assumed that wind and wave loading apply in the same direction. Fig. 7 shows the simulated wind forces for operational and parked conditions. It should be noted that even though values of wind loading are smaller than total wave loading, they have more impact on the dynamic responses as wind loading applies at higher height resulting in much larger moment values. Comparing Fig. 7a with Fig. 7b, it is clear that in the operational condition wind loading comprises a considerable mean constant value (around 650 $\mathrm{kN}$ in this simulation) and a turbulent component. This large mean constant force is due to the fact that the blades are faced toward the wind inflow at which most of the wind loading is facing the blades. On the other hand, in the parked condition shown in Fig. 7b, the mean component is around zero because in the parked condition the blades are pitched in a way that they are subjected to the minimum wind loading resulting in a mean value close to zero. 

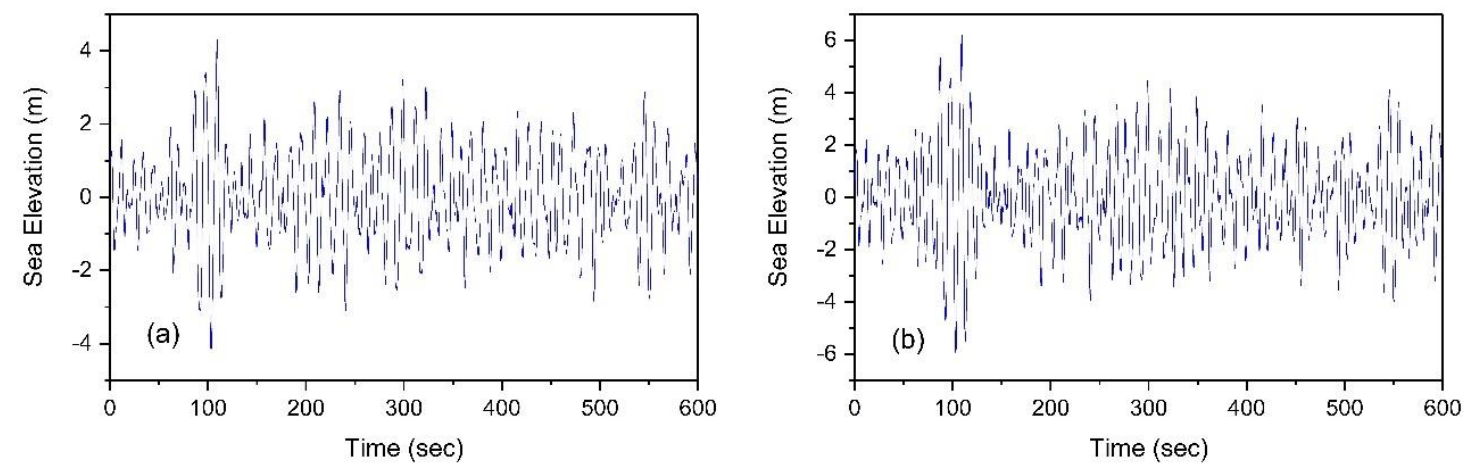

Fig. 5 Sea elevation time history (a) operational (b) parked
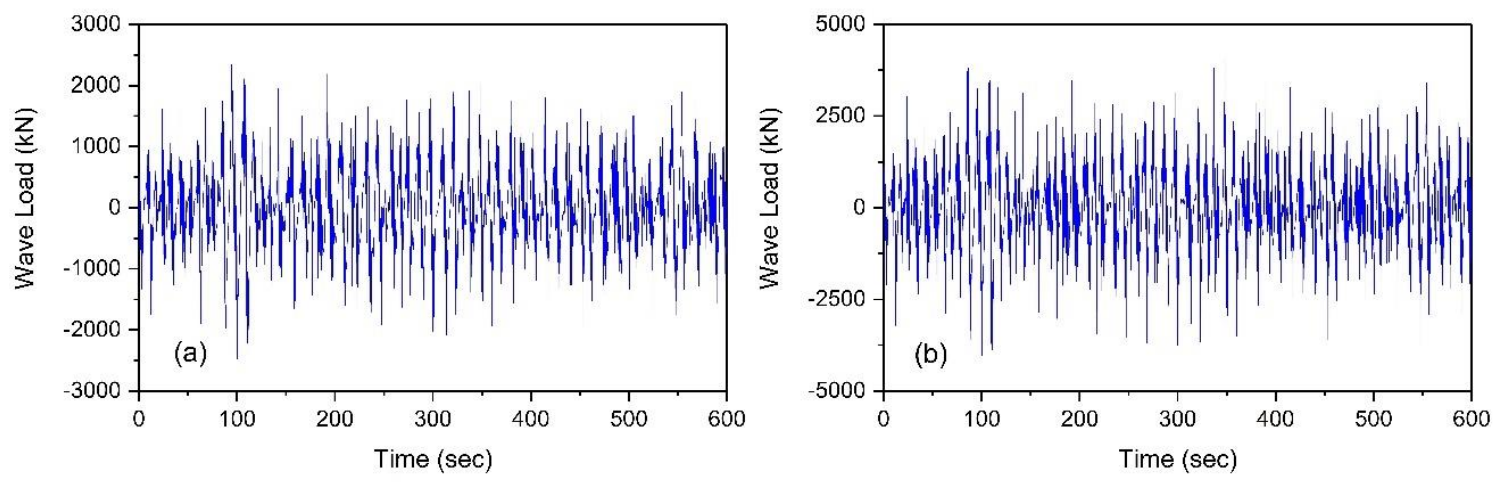

Fig. 6 Time history of total wave loading on the monopile (a) operational (b) parked
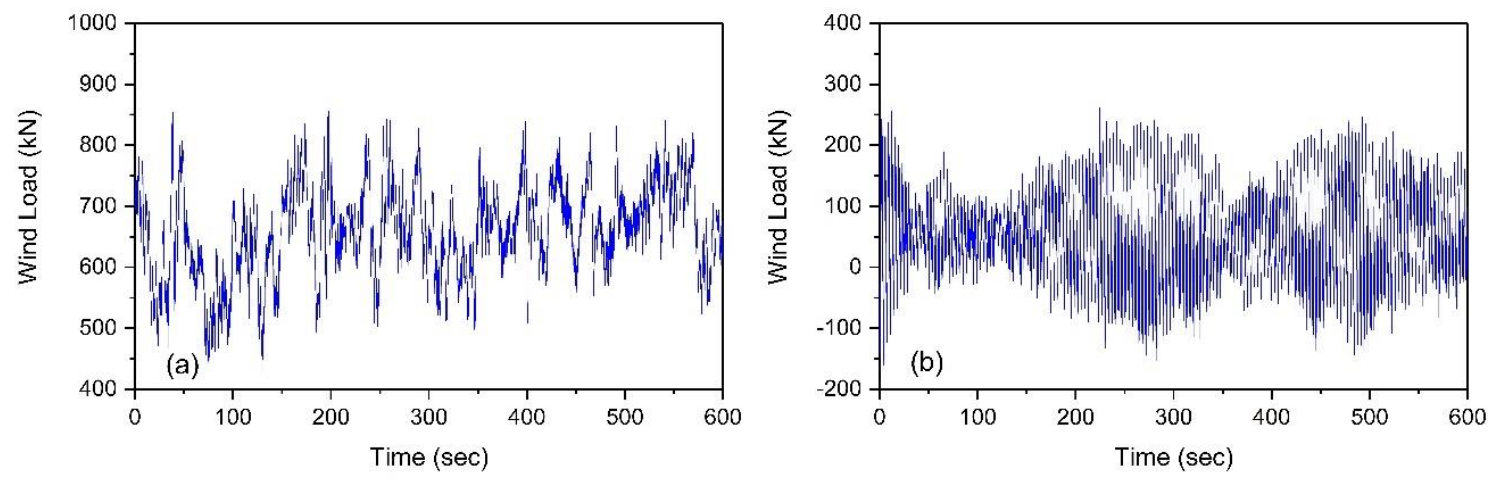

Fig. 7 Time history of total wind loading on the top of the tower (a) operational (b) parked

In order to give a preliminary insight into the impact of seismic loading on the dynamic responses, the responses of the system under only one seismic record are presented in the figures for the sake of brevity. Fig. 8 compares the responses of the structure under wave-wind loadings and wave-wind-seismic loadings without any structural control devices. At the first glance, it is clear that fore-aft displacement fluctuates around a high mean value of $0.5 \mathrm{~m}$ in the operational condition. However, this corresponding response for parked conditions has a very low mean value. This is again due to the fact that in operational conditions blades are positioned in a way to absorb the maximum of wind loading. It is worth mentioning that the maximum of deflection occurs at the instant of 118 s, 18 seconds after the earthquake motion starts. Furthermore, the maximum fore-aft displacement increases from around $0.76 \mathrm{~m}$ to $0.93 \mathrm{~m}$, resulting in $22 \%$ increase, when the earthquake excitation exists. This increase is more pronounced for the parked condition as the maximum of deflection increases from $0.1 \mathrm{~m}$ to $0.34 \mathrm{~m}$, resulting in $250 \%$ change. This jump in the fore-aft deflection affects the serviceability of the whole system since the devices such as inverters, transformers, and electrical generators are highly sensitive to excessive vibrations especially those caused by large accelerations. Therefore, implementation of a structural control device to mitigate this additional acceleration is necessary and assessed in the next sections. 

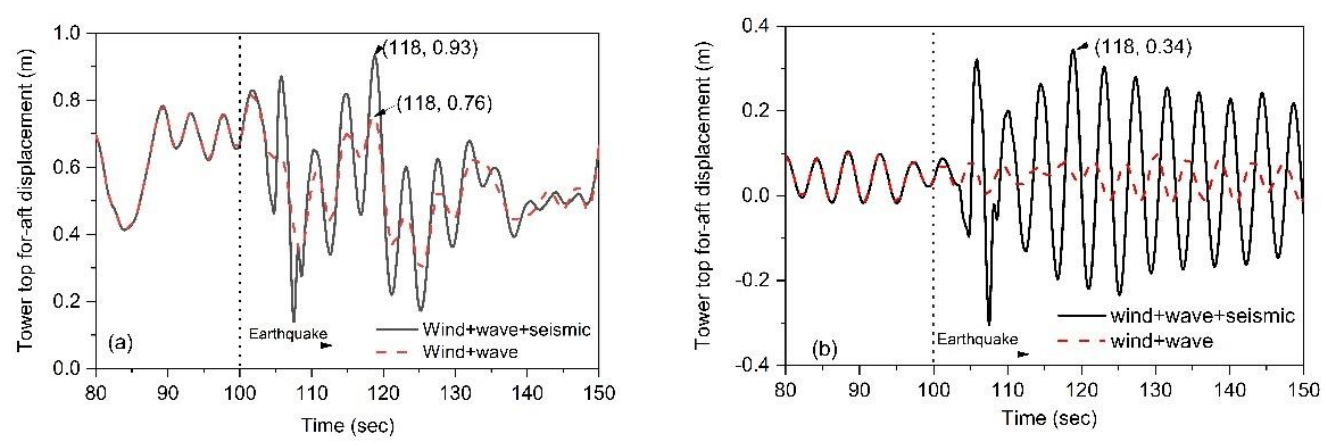

Fig. 8 Tower top fore-aft displacement time history (a) operational (b) parked

Fig.9 and Fig.10 show time history of base shear and base moment, respectively. The peak values occur at the instant of $105 \mathrm{sec}$. Comparing this with the corresponding peak values of deflection in Fig 8, it is clear that the pile experiences the maximum responses 13 seconds before the top of the tower. This is due to the high slenderness of the system. Comparing the base shear time histories for two loading conditions (Fig. 9a and Fig. 9b), the maximum values appear at the instant of $105 \mathrm{sec}$ and the values are almost identical. This shows that these maximum values are highly affected by seismic excitation. However, the corresponding peak values for base moments (Fig. 9a and Fig. 9b) are not identical. For instance, the base moment at the instant of $105 \mathrm{sec}$ is 99780 $\mathrm{kNm}$ for operational condition, whereas the corresponding value for the parked condition is $54660 \mathrm{kNm}$.
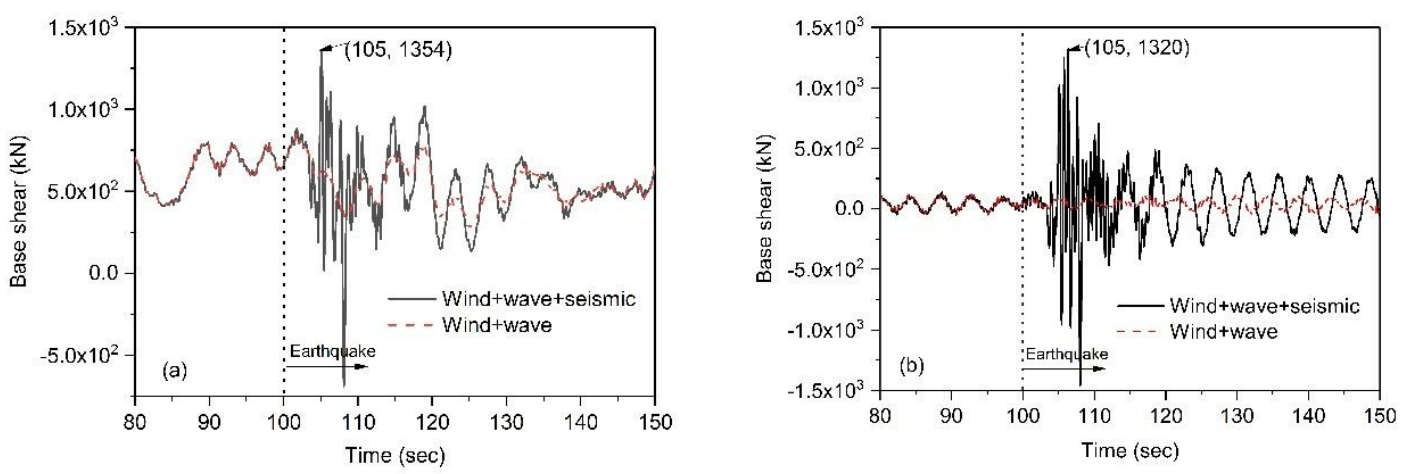

Fig. 9 Fore-aft base shear time history (a) operational (b) parked
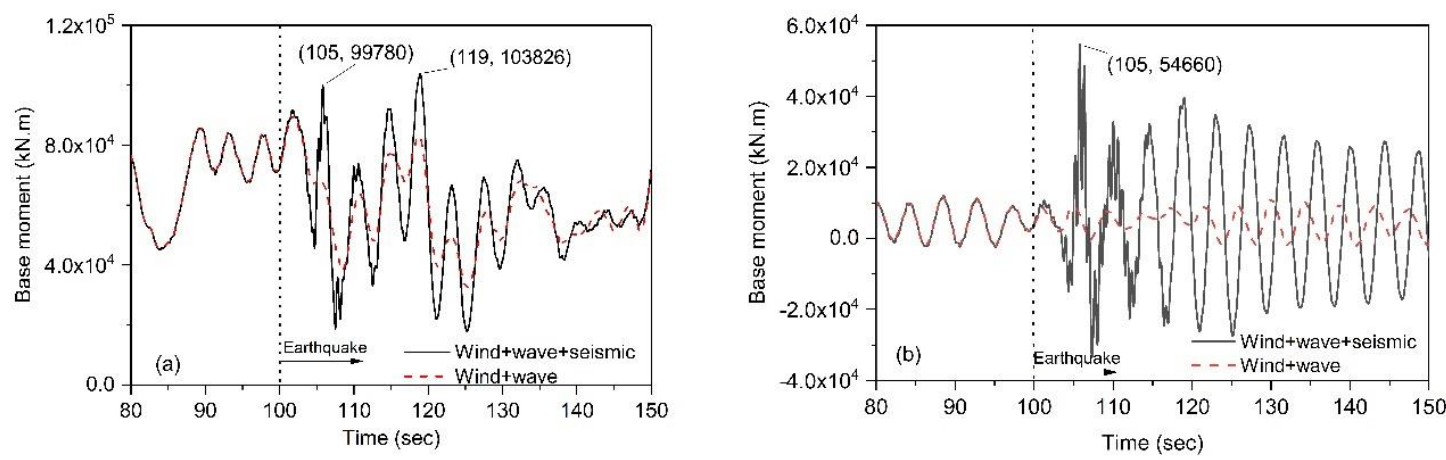

Fig. 10 Base moment time history (a) operational (b) parked

Fig. 11 shows the power spectral density (PSD) of tower top displacement for the operational and parked conditions. For the operational condition (Fig. 11a), the first peak appears close to zero due to energy spectrum from wind loading, and the second peak occurs at the frequency of $0.24 \mathrm{~Hz}$ which corresponds to the first natural frequency of the system. For the parked condition (Fig. 11b), there is a peak at the frequency of $0.24 \mathrm{~Hz}$ corresponding to the first natural frequency. In this figure, it is clear that the energy spectrum of wind with the 
frequencies lower than $0.1 \mathrm{~Hz}$ is much lower compared to the operational condition because in the parked condition the system is absorbing a small portion of wind loading as a result of pitching mechanism in the blades. Comparing the PSD plots with and without seismic loading, an increase in PSD especially for the frequencies close to the natural frequency of the system is observed due to earthquake motions. This increase in the peak values of PSD is more pronounced for the parked condition due to the fact that there is a lower total damping in the parked condition because of the lack of aerodynamic damping. Furthermore, the figure shows that earthquake energy lays in the broader frequency range.
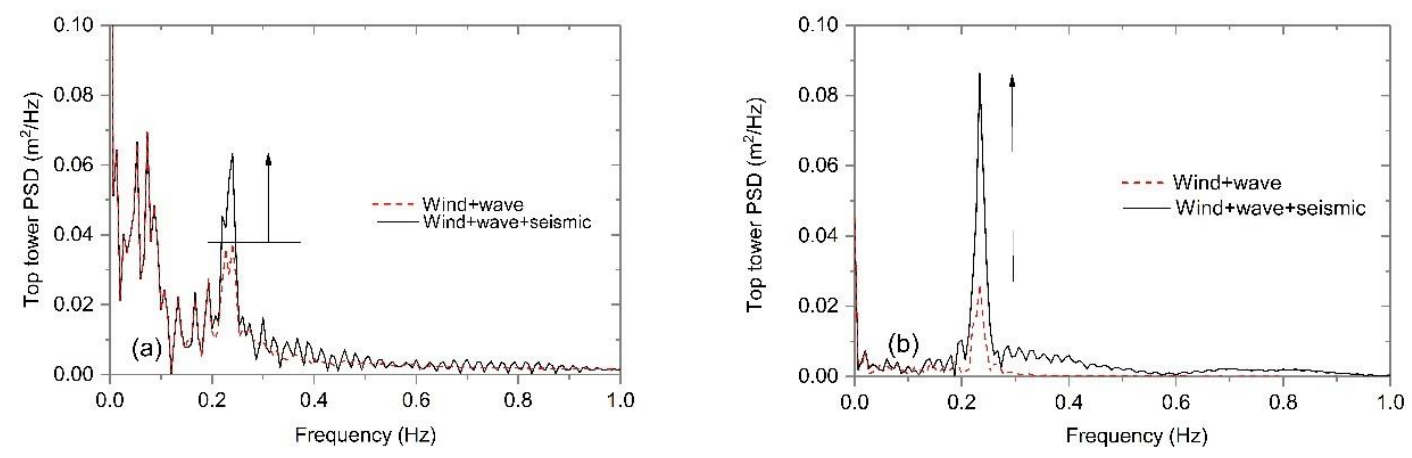

9

11

12

13

14

Fig. 11 PSD of the fore-aft top tower displacement (a) operational (b) parked

\subsection{Dynamic response of OWTs with TLCDs}

To mitigate the vibrations of offshore wind turbines subjected to environmental and seismic loadings, the baseline optimal TLCD as defined in Table 1 is used. Fig. 12 compares the responses of the structure under wave-windseismic loadings with and without the optimal TLCD. For two loading conditions, it is obvious that the TLCD reduces the amplitudes of vibration and this reduction is more pronounced after the instant of $100 \mathrm{sec}$ when the earthquake occurs. For the operational condition (Fig. 12a), the peak value decreases by $13 \%$ from $0.93 \mathrm{~m}$ to 0.81 $\mathrm{m}$ due to the extra damping caused by the TLCD. For the parked condition, the peak is halved from $0.34 \mathrm{~m}$ to 0.17 $\mathrm{m}$, resulting in $50 \%$ decrease.
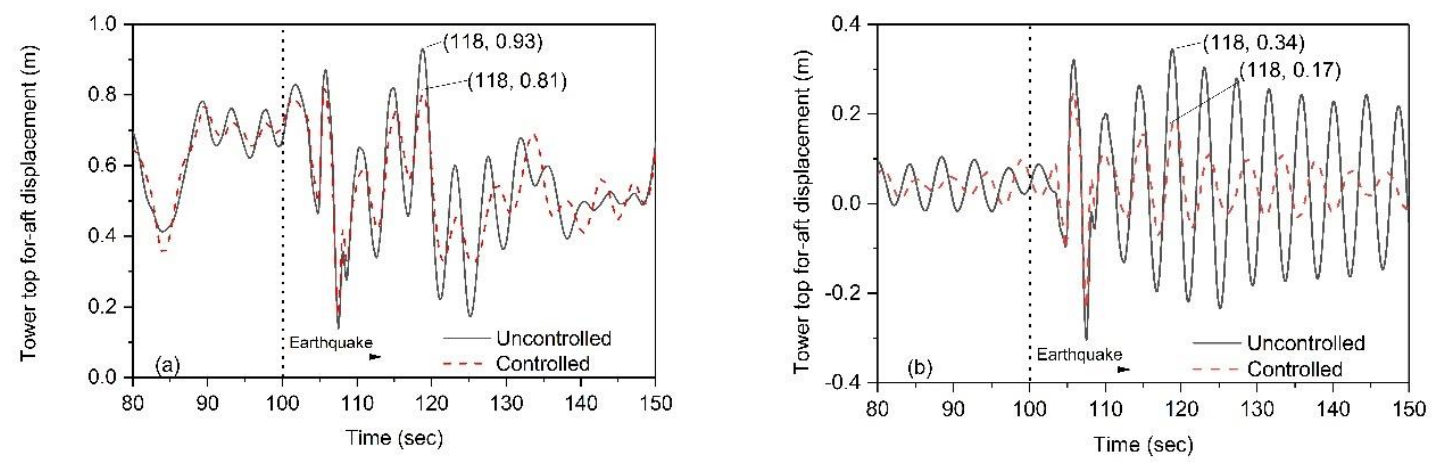

Fig. 12 Time history of tower top fore-aft displacement (a) operational (b) parked

Fig. 13 shows time histories of base shear forces. The figure shows that the TLCD is more efficient in mitigating the vibrations of seismic loading after the instant of $115 \mathrm{sec}$. This means that the TLCD is not able to work effectively in the first few seconds of the earthquake motions as it needs more time to adjust and respond to the seismic vibrations. For the vibrations before the instant of $115 \mathrm{sec}$, the controlled and uncontrolled systems have nearly similar base shear values. Fig. 14 compares the base moment time histories for the controlled and uncontrolled systems for two loading conditions. The similar trend for the base moment can be seen. The controlled system experiences $13 \%$ and $43 \%$ reduction in the peak values of the base moment for the operational and the parked condition, respectively. 

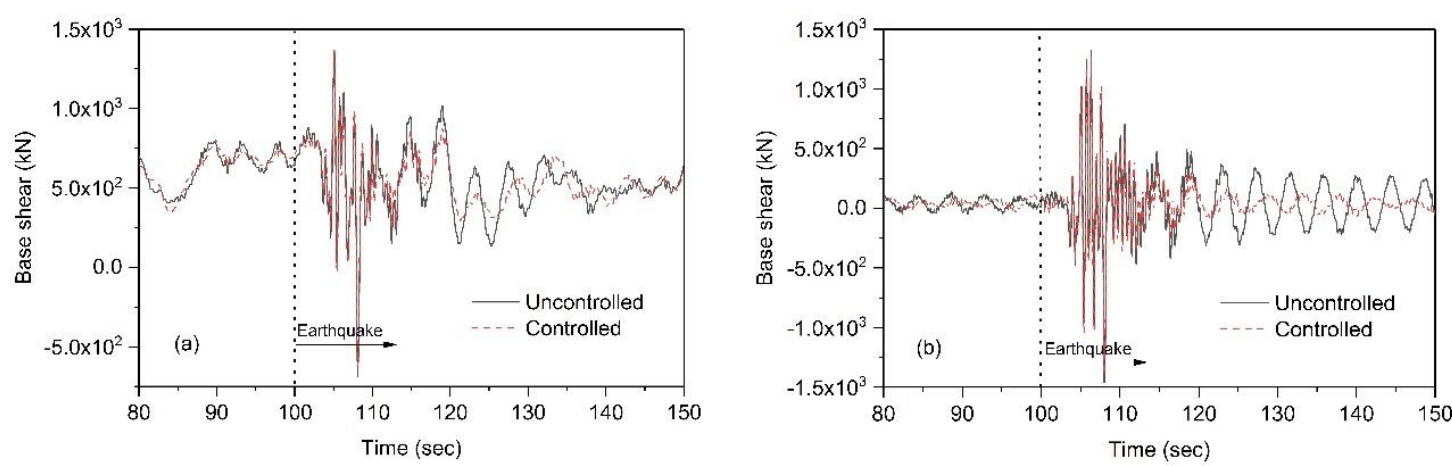

Fig. 13 Fore-aft base shear time history (a) operational (b) parked
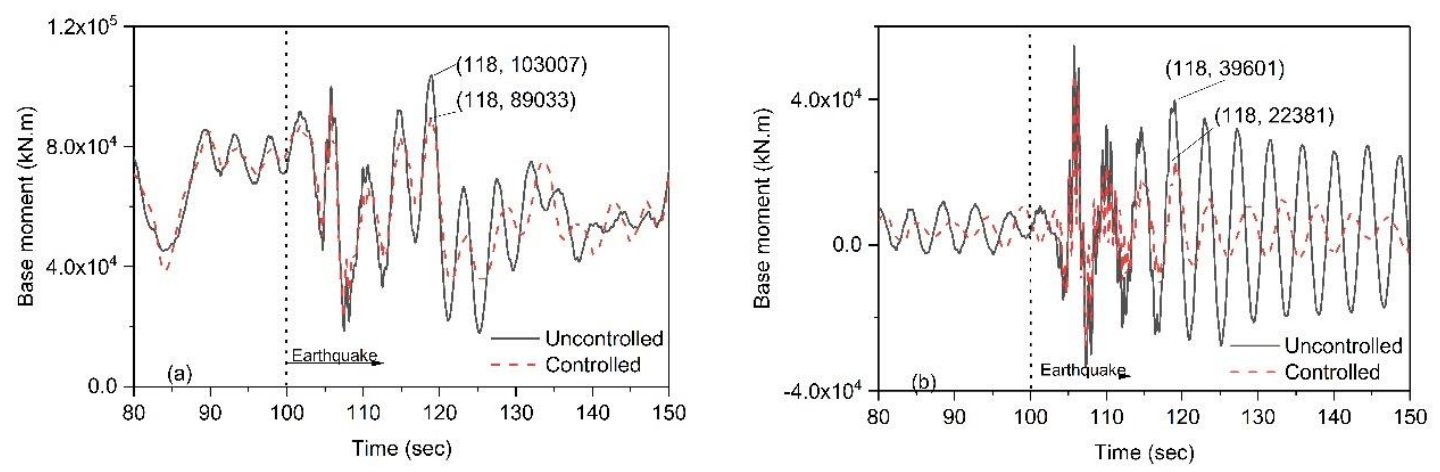

Fig. 14 Base moment time history (a) operational (b) parked

Fig. 15 shows the power spectral density (PSD) of tower top displacement for the controlled and uncontrolled system. For both loading conditions, the PSD values in the range close to the natural frequency of the system are reduced as the optimal structural control device is tuned to the natural frequency of the system. It is clear that the reduction in the peak of PSD is more significant for the parked condition.
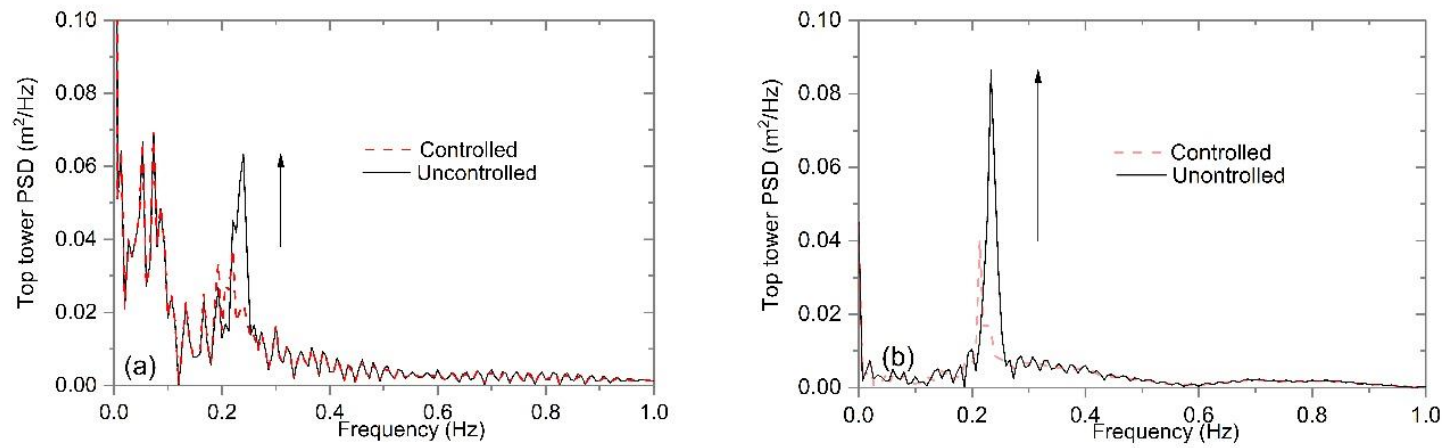

Fig. 15 PSD of fore-aft displacement for controlled and uncontrolled systems (a) operational (b) parked

To investigate the effectiveness of the structural control systems on the excessive vibration of offshore wind turbines, the standard deviation of fore-aft displacement is tracked since the standard deviation of dynamic responses is a better representation for the fluctuation level of vibration. The standard deviation is compared to the uncontrolled wind turbine. To quantify this, the reduction coefficient of standard deviation is used as follows:

$$
R_{\sigma}=\frac{\sigma_{\text {Uncontrolled }}-\sigma_{\text {Controlled }}}{\sigma_{\text {Uncontrolled }}}
$$

where $\sigma_{\text {Uncontrolled }}$ and $\sigma_{\text {Controlled }}$ are the standard deviation of fore-aft displacement of the top tower without and with TLCDs, respectively. 
To scrutinize the performance of the optimal structural control device for mitigating the structural responses under earthquake excitations, the dynamic response of offshore wind turbine is simulated under wave and wind loading in conjunction with earthquake ground motions with the peak ground acceleration ranging from $0.05 \mathrm{~g}$ to $0.95 \mathrm{~g}$. The earthquake accelerations are scaled based on predefined peak ground acceleration (PGA) range and an optimal TLCD with the chosen mass ratio of 0.025 and the reduction coefficient of standard deviation is calculated and plotted in Fig. 16a and Fig. 16b for operational and parked conditions, respectively. As can be seen in the figures, the reduction coefficients for most earthquake records decrease when the peak ground acceleration of the earthquakes increases. This means that the effectiveness of tuned liquid column dampers for mitigating vibration of offshore wind turbine systems is higher for low-intensity earthquake records. This is expected as tuned liquid column dampers are more efficient for low amplitude vibrations [19, 58]. For operational conditions, the reduction coefficient for two of earthquake records becomes even negative for peak ground accelerations larger than $0.3 \mathrm{~g}$ due to the existence of very large vibration amplitudes resulting in the inability of the dampers to perform. It should be noted that the probability of occurrence of earthquakes with low peak ground accelerations is higher than that of high-intensity earthquakes. The average of reduction coefficient for all records for operational and parked conditions are shown in Fig.16a and Fig.16b, respectively. The reduction coefficient varies between 12$20 \%$ for the operational condition for PGA ranging from $0.05 \mathrm{~g}$ to $0.95 \mathrm{~g}$. However, corresponding value for the parked condition is much higher, varying between $23-39 \%$. This trend can be justified since total damping of the system for the parked condition is lower due to the absence of aerodynamic damping and the TLCD compensates for it.
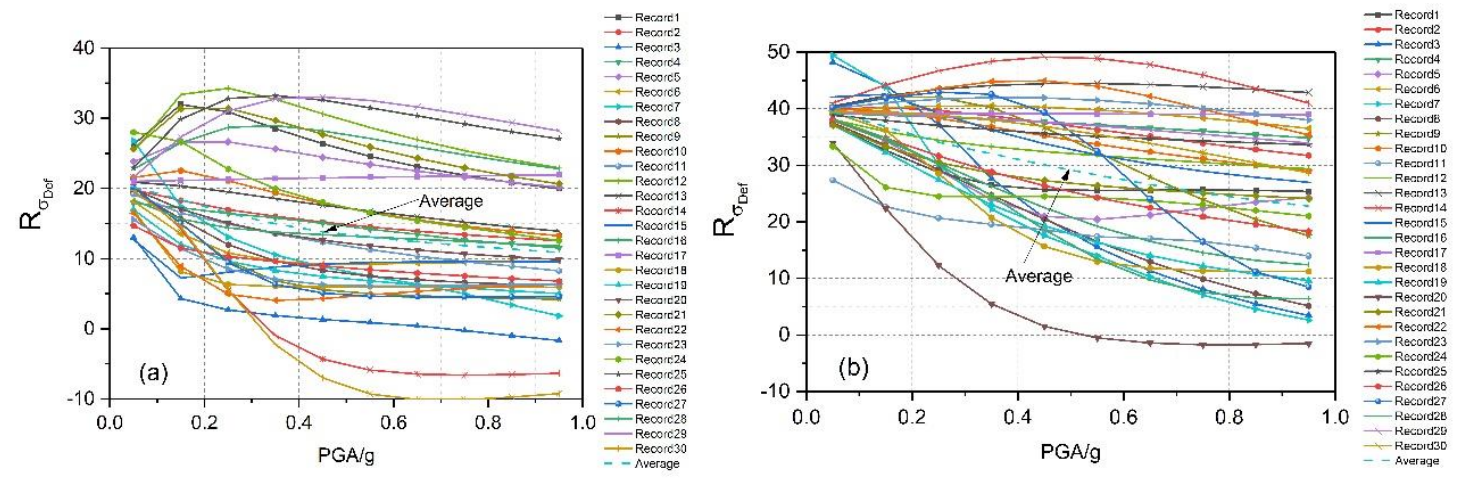

Fig. 16 Reduction coefficient of the standard deviation of dynamic responses under multi-hazard conditions with different PGAs (a) operational (b) parked

\subsection{Fragility Analysis}

The reliability improvements of TLCD-mounted wind turbines excited by environmental loading (wave and wind) in conjunction with earthquake ground motions are assessed by developing fragility curves. Excessive vibrations of wind turbines under multi-hazard damage the vibration-sensitive equipment inside the nacelle and reduce serviceability of the system resulting in inhibition of energy conversion [59]. Therefore, implementing structural control devices in the design of offshore wind turbines can improve the reliability of the mentioned equipment. The reliability improvements of the vibration controllers can be estimated by performing fragility analysis of the components [60]. In this study, a fragility analysis is performed based on the acceleration-based capacity limit state. In structural risk assessment, fragility functions are defined to estimate the probability of the event in which the demand $(D)$ reaches or exceeds a certain capacity limit $(C)$ for a given intensity measure $(I M)$ of seismic excitations.

37 The fragility function in Eq. (19) is assumed as a lognormal cumulative distribution function defined in the 
$1 \quad P[C \mid I M=x]=\Phi\left(\frac{\ln (x / \theta)}{\beta}\right)$

2 where $P[C \mid I M=x]$ is the probability that the demand of the structure exceeds the capacity under the excitation

3 of a ground motion with $I M=x, \Phi(\bullet)$ is the standard normal cumulative distribution function, $\theta$ is the median

4 values of the fragility function which can be defined as the $I M$ level with $50 \%$ probability of failure, and $\beta$ is the

5 dispersion of $I M$ (the standard deviation of $I M$ ). Generating fragility function curves based on the above formula

6 requires estimating $\theta$ and $\beta$ from the nonlinear structural analysis. Here we refer the estimation of these

7 parameters as $\hat{\theta}$ and $\hat{\beta}$.

8 There are various procedures for estimating fragility function parameters based on the nonlinear dynamic analysis.

9 The most common method is incremental dynamic analysis (IDA), in which ground motions are increased

10 incrementally to find the $I M$ level at which the demand surpasses the capacity of the structure [62]. Truncated

11 incremental dynamic analysis is the second method which is the modified version of IDA method in which the

12 lower number of samples are required [39]. Multiple stripes analysis (MSA) is another method, where a specified

13 selection of $I M$ levels for a group of ground motions are used and structural analyses are performed for each $I M$

14 level to estimate failure probability. Multiple stripes analysis is chosen for this study as the most appropriate 15 methodology since other methods require scaling ground motions up to very high values in order to find the $I M$ 16 level at which the criteria of failure is met and these $I M$ levels are not practical and may lead to large nonlinearities 17 and instabilities due to high slenderness of offshore wind turbine foundations. The second reason for choosing the 18 MSA method is that it is less computationally expensive.

19 Fig. 17 illustrates the flowchart of the methodology used in this research. In this method, nonlinear structural 20 analyses are performed at a discrete selection of $I M$ levels for a sample of ground motions. It should be noted that in this study the demand is chosen as the nacelle's accelerations since it is a measure of serviceability of the sensitive mechanical and electrical components inside the nacelle. The capacity in this study is the acceleration threshold at which the equipment inside the nacelle faces damages or misfunction. Here three acceleration thresholds of $7.5 \mathrm{~m} / \mathrm{s}^{2}, 12.5 \mathrm{~m} / \mathrm{s}^{2}$, and $17.5 \mathrm{~m} / \mathrm{s}^{2}$ corresponding to acceleration thresholds in which functionality of generators, inverters, and electrical controls can be affected, respectively [59]. 


\section{Nonlinear structural analysis}

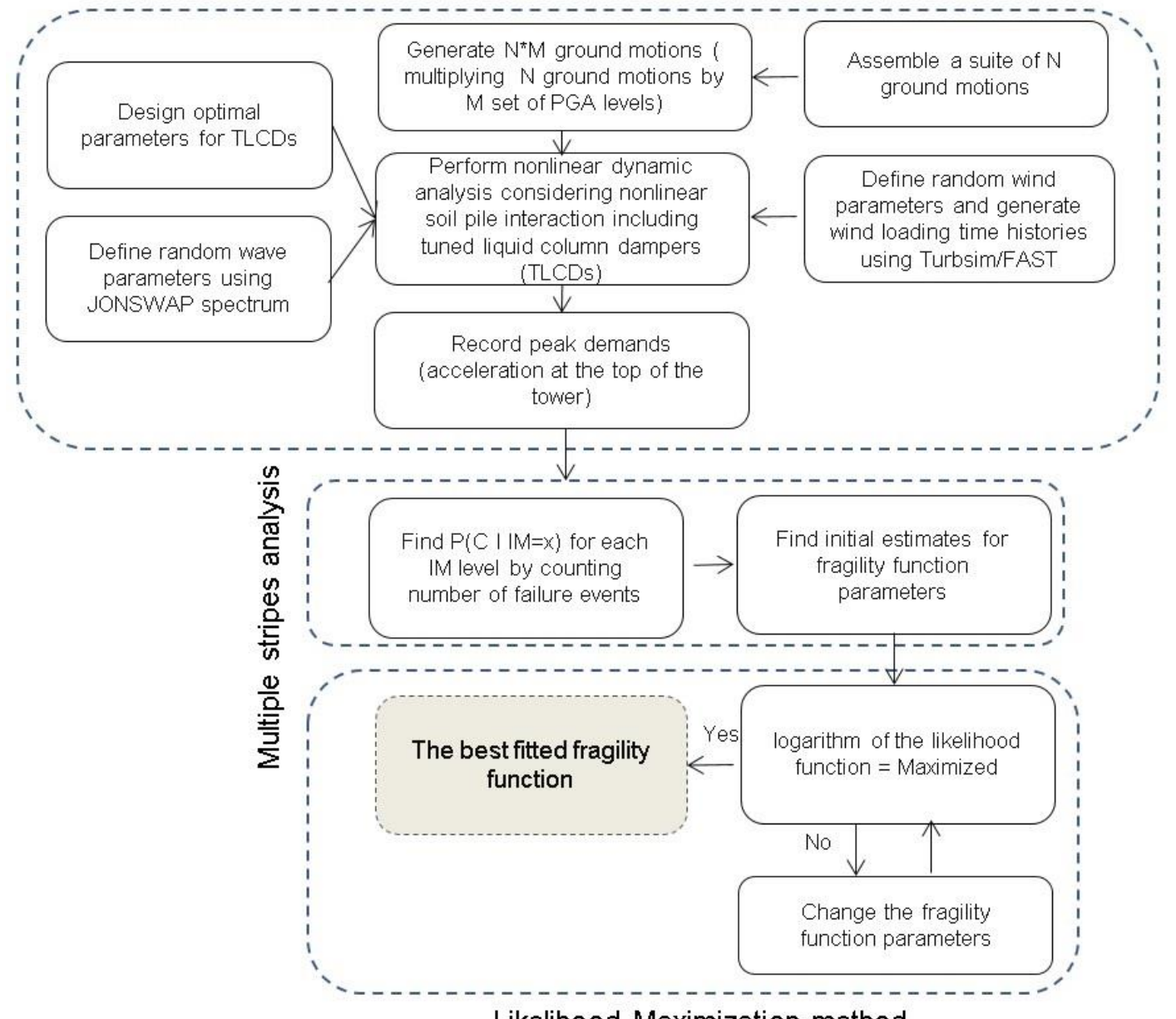

Likelihood Maximization method

Fig. 17 Fragility analysis based on MSA method

3 We can find the fraction of the ground motions at each intensity level $I M$ at which the demand (accelerations) 4 exceeds the capacity (acceleration threshold). The recorded data for the uncontrolled offshore wind turbine is 5 shown in Fig. 18 for three limit states. The probability of failure corresponding to each limit state at a given IM level can be calculated as the fraction of the records at which the peak acceleration of the nacelle exceeds the limit state. It can be seen that the number of failures increases with increasing $I M$ levels. Then similar MSA analysis with the same loading for the system controlled with the optimal TLCD is performed and the results are shown in Fig. 19. It can be seen that the points in the figure are shifted to lower values and number of the failures are decreased. 

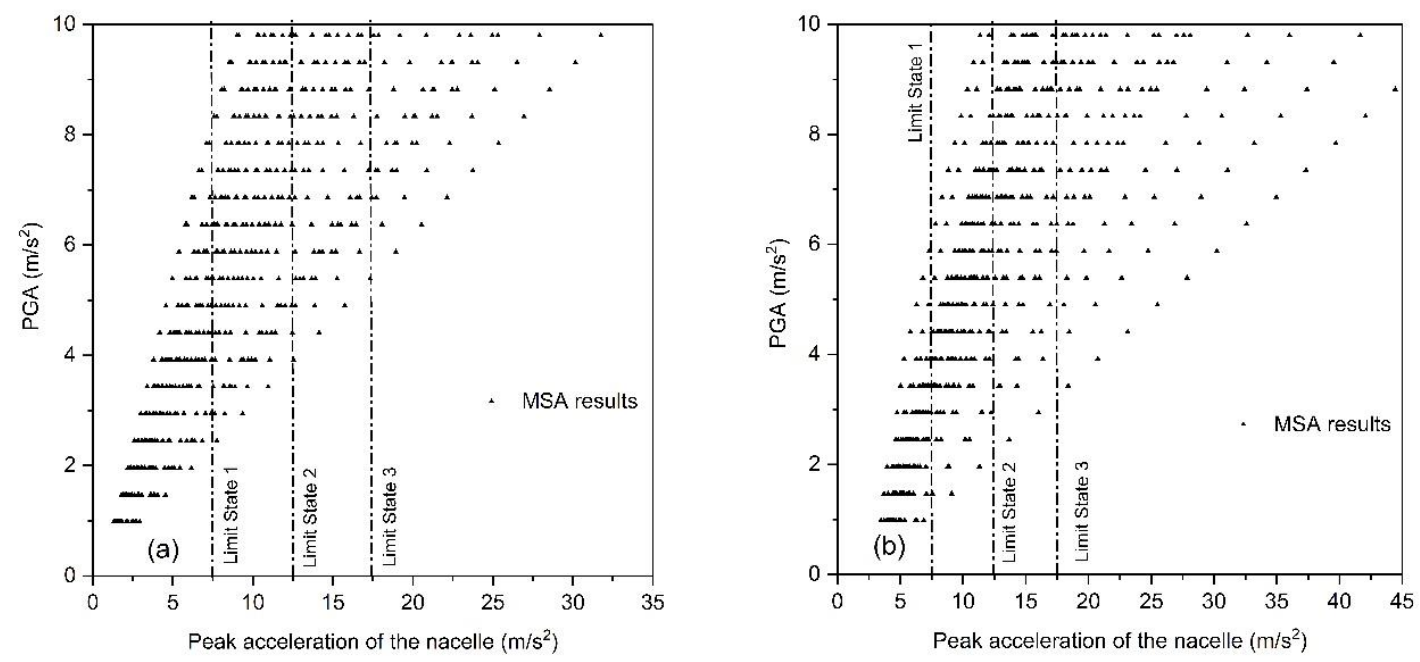

1

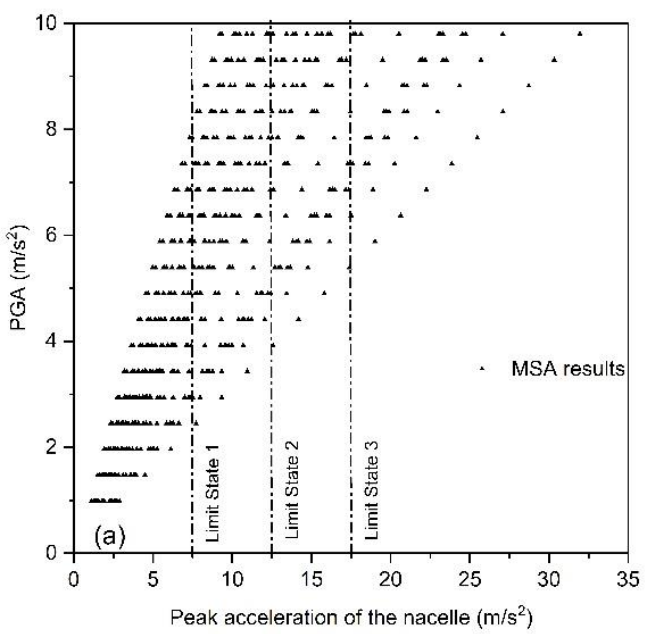

Fig. 18 MSA analysis results for the uncontrolled offshore wind turbine (a) operational (b) parked

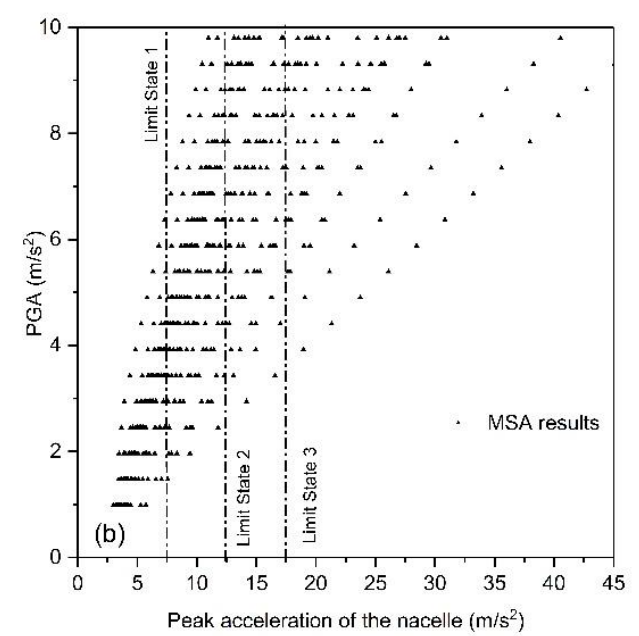

3

Fig. 19 MSA analysis results for the controlled offshore wind turbine (a) operational (b) parked

Using the results illustrated in Fig. (18-19), the fragility curves should be established. The method used in constructing fragility curves is Maximum Likelihood approach. If we assume that our observation of failure or no-failure for a given ground motion is independent of that of other ground motions, the probability of observing $z_{j}$ failures out of $n_{j}$ ground motion records at the intensity level of $I M=x_{j}$ can be defined as binominal distribution as

$P\left(z_{j}\right.$ failures under $n_{j}$ ground motions $)=\left(\begin{array}{c}n_{j} \\ z_{j}\end{array}\right) p_{j}^{z_{j}}\left(1-p_{j}\right)^{n_{j}-z_{j}}$

in which $p_{j}$ is the probability that a ground motion record with the intensity level of $I M=x_{j}$ causes the demand exceeds the capacity. The crucial part of the MSA method is to find a fragility function that predicts $p_{j}$ with the highest probability of the observed data obtained from the nonlinear structural analysis. This step is named as the 
maximum likelihood approach in which the likelihood is defined as the product of binomial probabilities obtained from Eq. (21) at each intensity level as

Likelihood $=\prod_{j=1}^{m}\left(\begin{array}{c}n_{j} \\ z_{j}\end{array}\right) p_{j}^{z_{j}}\left(1-p_{j}\right)^{n_{j}-z_{j}}$

where $\prod$ denotes a product, and $m$ is the number of intensity measure $I M$ levels. By substituting Eq. (20) into the above equation, the likelihood function can be defined using fragility function parameters as

Likelihood $=\prod_{j=1}^{m}\left(\begin{array}{c}n_{j} \\ z_{j}\end{array}\right) \Phi\left(\frac{\ln \left(x_{j} / \theta\right)}{\beta}\right)^{z_{j}}\left(1-\Phi\left(\frac{\ln \left(x_{j} / \theta\right)}{\beta}\right)\right)^{n_{j}-z_{j}}$

Then the most accurate fragility function parameters can be calculated by maximizing the likelihood function in an optimization solver in MATLAB. Since it is easier to use the logarithm of the likelihood function in our solver, the final maximization equation can be defined as

$$
\{\hat{\theta}, \hat{\beta}\}=\underset{\theta, \beta}{\arg \max } \sum_{j=1}^{m}\left\{\ln \left(\begin{array}{c}
n_{j} \\
z_{j}
\end{array}\right)+z_{j} \ln \Phi\left(\frac{\ln \left(x_{j} / \theta\right)}{\beta}\right)+\left(n_{j}-z_{j}\right) \ln \left(1-\Phi\left(\frac{\ln \left(x_{j} / \theta\right)}{\beta}\right)\right)\right\}
$$

The fragility function curves obtained from the estimated fragility parameters using Maximum Likelihood approach is plotted in Fig. 20 for only limit state 1 under the operational loadings for the sake of brevity. The fraction of analyses causing failure to a total number of analyses is plotted as well. The higher the value of Likelihood function calculated from Eq. (22), the closer the fragility curve to the points in Fig. 20.
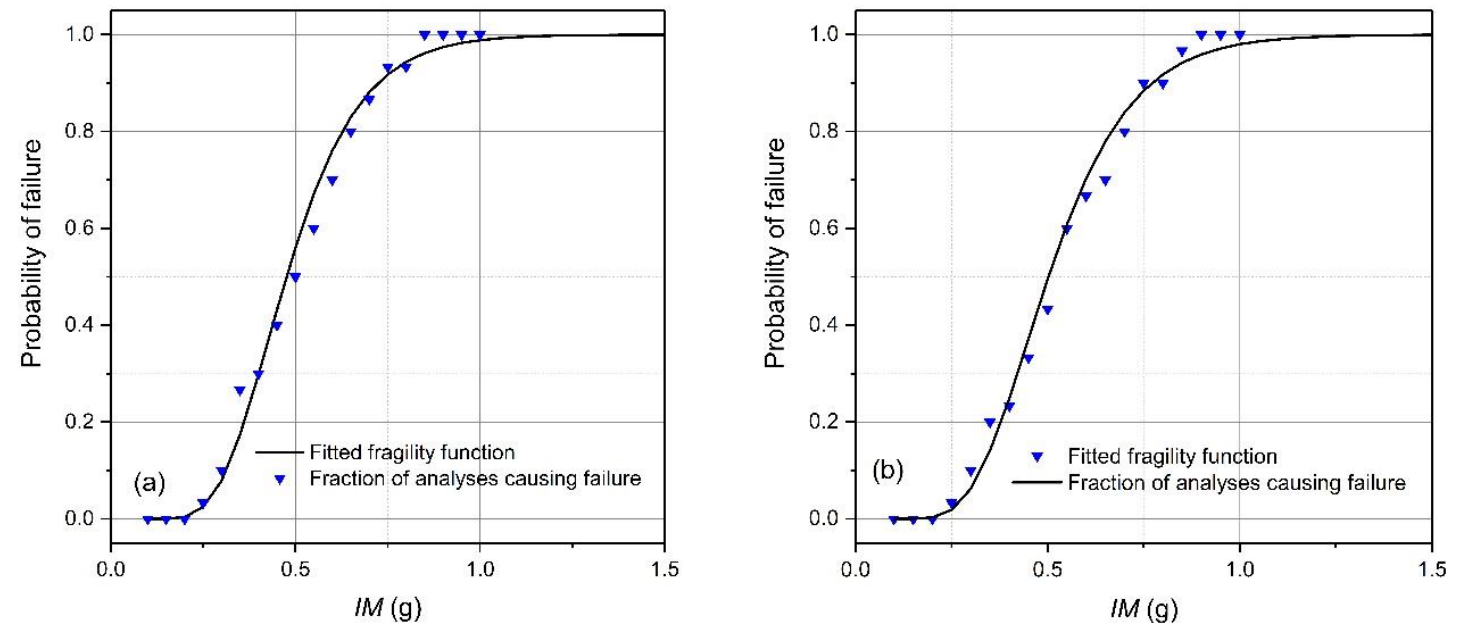

15

Fig. 20 Fragility curved obtained from the estimated fragility curve parameters based on Likelihood approach versus observed fractions of failures for operational loading for limit state 1 (a) uncontrolled (b) controlled

Fig. 21 shows fragility curves for the controlled and uncontrolled offshore wind turbines for three limit states under the operational and parked conditions. The solid lines correspond to the uncontrolled system in which there is no vibration control system and the dot lines correspond to the fragility curves of the controlled system. At the first glance, it is apparent that the fragility values for the parked condition at a given intensity measure are much higher than the corresponding fragility values for operational condition and this difference is more pronounced in lower intensity measures. Since lower intensity measures are more probable to occur, the reliability of equipment inside the nacelle is much lower in the parked conditions at lower intensity measures. For instance, the fragility of the uncontrolled system at $0.5 \mathrm{~g}$ intensity measure for the limit state 1 under the operational condition is $56 \%$, whereas the corresponding fragility value for the parked condition is $90 \%$, nearly $60 \%$ reduction in reliability. For 
limit state 2 , the fragility of the uncontrolled system under operational loading at $0.5 \mathrm{~g}$ intensity measure is $11 \%$, however, the corresponding value for the parked condition is $31 \%$, nearly tripled. This highlights the importance of a structural control device especially for the parked condition in which the lack of aerodynamic damping causes larger excessive vibrations, consequently lower reliability.
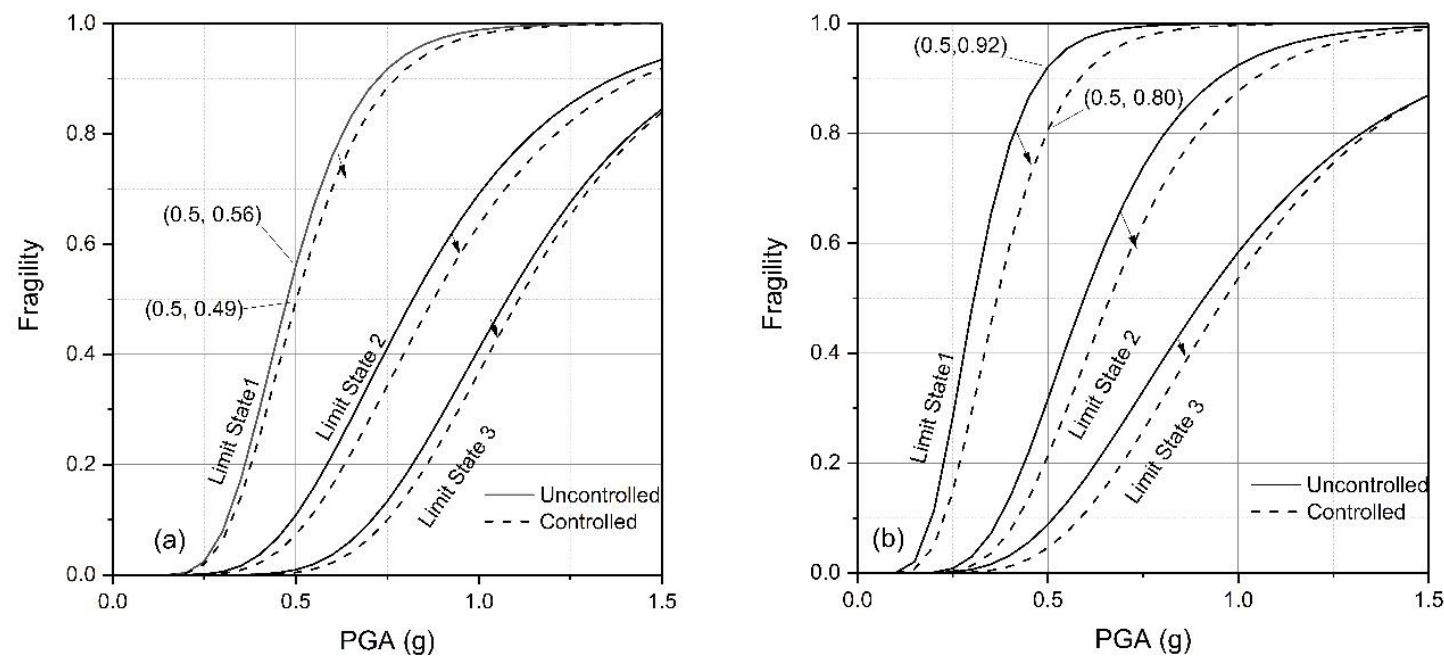

5

Fig. 21 Reduction in fragility using the optimal TLCD for three limit states (a) operational (b) parked

Looking into the effect of the structural control device, it is clear that there is a shift to lower fragility values when the system is controlled with the optimal TLCD. For instance, the fragility of exceeding acceleration capacity of $0.5 \mathrm{~g}$ for the operational condition is reduced from $56 \%$ to $49 \%$, representing $7 \%$ decrease in fragility values. This fragility reduction is approximately doubled for the parked condition in which fragility is reduced from $92 \%$ to $80 \%$, resulting in $12 \%$ reduction in fragility. Table 7 provides the fragility values and fragility reduction gained from the optimal TLCD for the predefined limit states under two loading conditions. The maximum fragility reduction obtained from the tuned liquid column damper for operational load case is $9 \%$, however, the corresponding maximum fragility reduction for the parked condition is $15 \%$. This is expected because total damping of the system for the parked condition is low due to the lack of aerodynamic damping and a structural control device can compensate for this low damping value and boost the reliability of the system. The inclusion of an optimal tuned liquid column damper in the system reduces the overall fragility of the equipment, resulting in an increase in reliability of the system. This increases the energy conversion by reducing the number of interruptions and emergency shutdowns and consequently decreasing the number of maintenances required after the emergency shutdowns. 
Fragility values corresponding to three intensity measures for three limit states for wind turbines with and without TLCDs

\begin{tabular}{|c|c|c|c|c|c|c|c|}
\hline \multirow[b]{3}{*}{ Limit States } & \multicolumn{4}{|c|}{ Operational Condition (LC1) } & \multicolumn{3}{|c|}{ Parked Condition (LC2) } \\
\hline & & \multicolumn{6}{|c|}{ Intensity Measures $\left(\mathrm{m} / \mathrm{s}^{2}\right)$} \\
\hline & Fragility & $I M=0.5 g$ & $I M=0.75 g$ & $I M=g$ & $I M=0.5 g$ & $I M=0.75 g$ & $I M=g$ \\
\hline \multirow{3}{*}{$\begin{array}{l}\text { Limit State } 1 \\
\left(L S=7.5 m / s^{2}\right)\end{array}$} & $P_{\text {Uncoutrolled }}$ & $56 \%$ & $91 \%$ & $98 \%$ & $93 \%$ & $99 \%$ & $100 \%$ \\
\hline & $P_{\text {Controlled }}$ & $49 \%$ & $88 \%$ & $97 \%$ & $80 \%$ & $97 \%$ & $99 \%$ \\
\hline & $P_{\text {reduction }}$ & $7 \%$ & $3 \%$ & $1 \%$ & $13 \%$ & $2 \%$ & $1 \%$ \\
\hline \multirow{3}{*}{$\begin{array}{c}\text { Limit State } 2 \\
\left(L S=12.5 m / s^{2}\right)\end{array}$} & $P_{\text {Uncourrolled }}$ & $11 \%$ & $41 \%$ & $69 \%$ & $31 \%$ & $74 \%$ & $92 \%$ \\
\hline & $P_{\text {Controlled }}$ & $7 \%$ & $34 \%$ & $63 \%$ & $21 \%$ & $61 \%$ & $87 \%$ \\
\hline & $P_{\text {reduction }}$ & $4 \%$ & $7 \%$ & $6 \%$ & $10 \%$ & $13 \%$ & $5 \%$ \\
\hline \multirow{3}{*}{$\begin{array}{c}\text { Limit State } 3 \\
\left(L S=17.5 m / s^{2}\right)\end{array}$} & $P_{\text {Uncourrolled }}$ & $1 \%$ & $13 \%$ & $41 \%$ & $9 \%$ & $33 \%$ & $58 \%$ \\
\hline & $P_{\text {Controlled }}$ & $0 \%$ & $9 \%$ & $36 \%$ & $4 \%$ & $25 \%$ & $53 \%$ \\
\hline & $P_{\text {reduction }}$ & $1 \%$ & $4 \%$ & $5 \%$ & $5 \%$ & $8 \%$ & $5 \%$ \\
\hline
\end{tabular}

\section{CONCLUSION}

7

In this paper, a numerical model of an offshore wind turbine controlled by optimal tuned mass liquid dampers (TLCDs) subjected to wind, wave, and earthquake excitations are established. The developed MATLAB code uses a nonlinear dynamic solution to consider the nonlinearities of TLCDs as well as soil-pile interaction. Numerical analyses are carried out for operational and non-operational loading in conjunction with seismic excitation to investigate the effectiveness of TLCD in reducing dynamic responses of multi-hazard conditions. The results show that the optimal TLCDs reduce the standard deviation of deflections of the top of tower up to $49 \%$. It is found that the TLCDs show a better performance in mitigating undesired vibrations caused by lowintensity earthquakes rather than very high-intensity earthquakes.

With regard to fragility analysis, three limit state thresholds corresponding to high, medium and low sensitive equipment are defined. Multiple stipes analysis approach is utilized to construct empirical cumulative distribution. Having used the Likelihood Maximization approach, the fragility function curves are obtained for the predefined limit states. The fragility values decrease with the inclusion of the tuned liquid column damper for all cases, resulting in a boost in the reliability of the system under multi-hazard conditions. However, this fragility reduction varies for different limit states and intensity measures. The maximum fragility reduction is observed for medium and high sensitive equipment up to $13 \%$. The corresponding values for low sensitive equipment are lower. Furthermore, the results show that the fragility reduction offered by the tuned liquid column dampers is higher for low-intensity earthquakes. In addition, the corresponding values for the parked condition are larger due to the lack of aerodynamic damping in this condition. Therefore, an optimal TLCD is found to show a robust performance for the application of offshore wind turbines subjected to multi-hazard excitations especially in parked conditions and implementation of these devices can result in an increase of overall reliability of the system, especially under low-intensity earthquake motions. Consequently, it reduces downtime and maintenance needs resulting in higher rates of energy conversion. Future research efforts can be focused on assessment of reliability improvement offered by more optimized structural control devices including semi-active and active dampers. 


\section{ACKNOWLEDGEMENT}

The authors would like to acknowledge the University of Strathclyde scholarship to carry out this research.

\section{REFERENCES}

1. Symans, M.D. and M.C. Constantinou, Semi-active control systems for seismic protection of structures: a state-of-the-art review. Engineering Structures, 1999. 21(6): p. 469-487.

2. Lackner, M.A. and M.A. Rotea, Structural control of floating wind turbines. Mechatronics, 2011b. 21(4): p. 704-719.

3. Yilmaz, O.C., The Optimization of Offshore Wind Turbine Towers Using Passive Tuned Mass Dampers. 2012, University of Massachusetts.

4. Stewart, G.M. and M.A. Lackner, The impact of passive tuned mass dampers and wind-wave misalignment on offshore wind turbine loads. Engineering Structures, 2014. 73: p. 54-61.

5. Stewart, G. and M. Lackner, Offshore Wind Turbine Load Reduction Employing Optimal Passive Tuned Mass Damping Systems. IEEE Transactions on Control Systems Technology, 2013. 21(4): p. 1090-1104.

6. Lackner, M.A. and M.A. Rotea, Passive structural control of offshore wind turbines. Wind Energy, 2011a. 14(3): p. 373-388.

7. Fitzgerald, B., B. Basu, and S.R.K. Nielsen, Active tuned mass dampers for control of in-plane vibrations of wind turbine blades. Structural Control and Health Monitoring, 2013. 20(12): p. 1377-1396.

8. He, E.M., Ya Qi Hu, and G.L.Y. Yang Zhang, Vibration and Load Suppression of Offshore Floating Wind Turbine. Advanced Materials Research, 2014. 1025-1026: p. 891-896.

9. Fitzgerald, B. and B. Basu, Active Tuned Mass Damper Control of Wind Turbine Nacelle/Tower Vibrations with Damaged Foundations. Key Engineering Materials, 2013. 569-570: p. 660-667.

10. Dinh, V.-N. and B. Basu, Passive control of floating offshore wind turbine nacelle and spar vibrations by multiple tuned mass dampers. Structural Control and Health Monitoring, 2015. 22(1): p. 152-176.

11. Zuo, H., K. Bi, and $\mathrm{H}$. Hao, Using multiple tuned mass dampers to control offshore wind turbine vibrations under multiple hazards. Engineering Structures, 2017. 141: p. 303-315.

12. Sun, C., Semi-active control of monopile offshore wind turbines under multi-hazards. Mechanical Systems and Signal Processing, 2018. 99: p. 285-305.

13. Cao, L. and C. Li, Tuned tandem mass dampers-inerters with broadband high effectiveness for structures under white noise base excitations. Structural Control and Health Monitoring, 2019. 26(4): p. e2319.

14. $\mathrm{Li}, \mathrm{C}$. and W. Qu, Optimum properties of multiple tuned mass dampers for reduction of translational and torsional response of structures subject to ground acceleration. Engineering Structures, 2006. 28(4): p. 472-494.

15. Jangid, R., Dynamic characteristics of structures with multiple tuned mass dampers. Structural Engineering and Mechanics, 1995. 3(5): p. 497-509.

16. Jangid, R., Optimum multiple tuned mass dampers for base-excited undamped system. Earthquake engineering \& structural dynamics, 1999. 28(9): p. 1041-1049.

17. Sakai, F., S. Takeda, and T. Tamaki. Tuned liquid column damper-new type device for suppression of building vibrations. in Highrise Buildings. 1989. Nanjing, China.

18. Ghaemmaghami, A.R., R. Kianoush, and O. Mercan, Numerical modeling of dynamic behavior of annular tuned liquid dampers for the application in wind towers under seismic loading. Journal of Vibration and Control, 2015. 22(18): p. 3858-3876. 
19. Colwell, S. and B. Basu, Tuned liquid column dampers in offshore wind turbines for structural control. Engineering Structures, 2009. 31(2): p. 358-368.

20. Zhang, Z., B. Basu, and S.R.K. Nielsen, Tuned liquid column dampers for mitigation of edgewise vibrations in rotating wind turbine blades. Structural Control and Health Monitoring, 2015. 22(3): p. 500-517.

21. J, A. and B. B. Vibration control of wind turbine blades using tuned liquid dampers. in the eleventh international conference on civil, structural and environmental, engineering computing. 2007. Stirlingshire, UK.

22. Mensah, A.F. and L. Dueñas-Osorio, Improved reliability of wind turbine towers with tuned liquid column dampers (TLCDs). Structural Safety, 2014. 47: p. 78-86.

23. Di Matteo, A., M. Di Paola, and A. Pirrotta, Innovative modeling of tuned liquid column damper controlled structures. Smart Struct. Syst, 2016. 18(1): p. 117-138.

24. Di Matteo, A., et al., Optimal tuning of tuned liquid column damper systems in random vibration by means of an approximate formulation. Meccanica, 2015. 50(3): p. 795-808.

25. Coudurier, C., O. Lepreux, and N. Petit, Modelling of a tuned liquid multi-column damper. Application to floating wind turbine for improved robustness against wave incidence. Ocean Engineering, 2018. 165: p. 277-292.

26. Buckley, T., et al., Mitigating the structural vibrations of wind turbines using tuned liquid column damper considering soil-structure interaction. Renewable Energy, 2018. 120: p. 322341.

27. Prowell, I., et al., Experimental and numerical seismic response of a $65 \mathrm{~kW}$ wind turbine. Journal of Earthquake Engineering, 2009. 13(8): p. 1172-1190.

28. Prowell, I., et al., Shake table testing and numerical simulation of a utility-scale wind turbine including operational effects. Wind Energy, 2014. 17(7): p. 997-1016.

29. Zhao, X. and P. Maisser, Seismic response analysis of wind turbine towers including soilstructure interaction. Proceedings of the Institution of Mechanical Engineers, Part K: Journal of Multi-body Dynamics, 2006. 220(1): p. 53-61.

30. Zhao, X., P. Maißer, and J. Wu, A new multibody modelling methodology for wind turbine structures using a cardanic joint beam element. Renewable Energy, 2007. 32(3): p. 532-546.

31. Bazeos, N., et al., Static, seismic and stability analyses of a prototype wind turbine steel tower. Engineering Structures, 2002. 24(8): p. 1015-1025.

32. Witcher, D., Seismic analysis of wind turbines in the time domain. Wind Energy, 2005. 8(1): p. 81-91.

33. Song, B., Y. Yi, and J.C. Wu, Study on Seismic Dynamic Response of Offshore Wind Turbine Tower with Monopile Foundation Based on M Method. Advanced Materials Research, 2013. 663: p. 686-691.

34. Alati, N., G. Failla, and F. Arena, Seismic analysis of offshore wind turbines on bottom-fixed support structures. Philosophical Transactions of the Royal Society A: Mathematical, Physical and Engineering Sciences, 2015. 373(2035).

35. Jin, X., H. Liu, and W. Ju, Wind Turbine Seismic Load Analysis Based on Numerical Calculation. 2014, 2014. 60(10): p. 11.

36. Nuta, E., C. Christopoulos, and J.A. Packer, Methodology for seismic risk assessment for tubular steel wind turbine towers: application to Canadian seismic environment. Canadian Journal of Civil Engineering, 2011. 38(3): p. 293-304.

37. Mardfekri, M. and P. Gardoni, Multi-hazard reliability assessment of offshore wind turbines. Wind Energy, 2015. 18(8): p. 1433-1450.

38. Kim, D.H., S.G. Lee, and I.K. Lee, Seismic fragility analysis of $5 \mathrm{MW}$ offshore wind turbine. Renewable energy, 2014. 65: p. 250-256.

39. Baker, J.W., Efficient analytical fragility function fitting using dynamic structural analysis. Earthquake Spectra, 2015. 31(1): p. 579-599. 
40. Newmark, N.M., A method of computation for structural dynamics. Journal of the engineering mechanics division, 1959. 85(3): p. 67-94.

41. Wu, J.-C., et al., Design guidelines for tuned liquid column damper for structures responding to wind. Engineering Structures, 2005. 27(13): p. 1893-1905.

42. Jonkman, J.M. and M.L. Buhl Jr, FAST User's Guide-Updated August 2005. 2005, National Renewable Energy Laboratory (NREL), Golden, CO.

43. Jonkman, J., W. Musial, and W. Musial, Offshore Code Comparison Collaboration (OC3) for IEA Task 23 Offshore Wind Technology and Deployment. 2010, National Renewable Energy Laboratory.

44. Jonkman, J., et al., Definition of a 5-MW Reference Wind Turbine for Offshore System Development. 2009, National Renewable Energy Laboratory.

45. Institute, A.P., Recommended Practice for Planning, Designing and Constructing Fixed Offshore Platforms-Working Stress Design. 2002.

46. Doherty, P. and K. Gavin, Laterally loaded monopile design for offshore wind farms. Proceedings of the ICE - Energy, 2012. 165(1): p. 7-17.

47. Kaimal, J.C., et al., Spectral characteristics of surface-layer turbulence. Quarterly Journal of the Royal Meteorological Society, 1972. 98(417): p. 563-589.

48. Murtagh, P.J., B. Basu, and B.M. Broderick, Along-wind response of a wind turbine tower with blade coupling subjected to rotationally sampled wind loading. Engineering Structures, 2005. 27(8): p. 1209-1219.

49. Commission, I.E., IEC 61400 Design requirements for offshore wind turbines. 2009.

50. Jonkman, B.J., TurbSim user's guide: Version 1.50. 2009, National Renewable Energy Lab.(NREL), Golden, CO (United States).

51. DNV, O.S.D.-O., J101: Design of Offshore Wind Turbine Structures. Det Norske Veritas, 2004.

52. (DNV), D.N.V., DNV-RP-C205: environmental conditions and environmental load. 2010: Norway.

53. Hasselmann, K., et al., Measurements of wind-wave growth and swell decay during the Joint North Sea Wave Project (JONSWAP). Ergänzungsheft 8-12, 1973.

54. Chiou, B., et al., NGA project strong-motion database. Earthquake Spectra, 2008. 24(1): p. 2344.

55. Doherty, P. and K. Gavin, Laterally loaded monopile design for offshore wind farms. Proc. Inst. Civ. Eng.-Energy, 2011. 165(1).

56. Lavassas, I., et al., Analysis and design of the prototype of a steel 1-MW wind turbine tower. Engineering structures, 2003. 25(8): p. 1097-1106.

57. Valamanesh, V. and A. Myers, Aerodynamic damping and seismic response of horizontal axis wind turbine towers. Journal of Structural Engineering, 2014. 140(11): p. 04014090.

58. Ghafory-Ashtiany, M., M. Mousavi, and A. Azarbakht, Strong ground motion record selection for the reliable prediction of the mean seismic collapse capacity of a structure group. Earthquake Engineering \& Structural Dynamics, 2011. 40(6): p. 691-708.

59. Dueñas-Osorio, L. and B. Basu, Unavailability of wind turbines due to wind-induced accelerations. Engineering Structures, 2008. 30(4): p. 885-893.

60. Choi, S.-K., Reliability-based structural design [internet resource], ed. R.V. Grandhi, A.C. Robert, and Springerlink. 2007: London : Springer.

61. Porter, K., R. Kennedy, and R. Bachman, Creating fragility functions for performance-based earthquake engineering. Earthquake Spectra, 2007. 23(2): p. 471-489.

62. Vamvatsikos, D. and C.A. Cornell, Incremental dynamic analysis. Earthquake Engineering \& Structural Dynamics, 2002. 31(3): p. 491-514. 


\section{Appendix}

2 Earthquake records

\begin{tabular}{llllll}
\hline ID & Earthquake & Magnitude & Year & Record Station & Soil Type \\
\hline 1 & Kobe, Japan & 6.9 & 1995 & Kobe University & B \\
2 & Northridge-01 & 6.69 & 1994 & 17645 & $\mathrm{D}$ \\
3 & Northridge-Landers & 7.28 & 1992 & 17645 Saticoy St & $\mathrm{D}$ \\
4 & Northbridge-Narrows01 & 5.99 & 1987 & 17645 Saticoy St & $\mathrm{D}$ \\
5 & Tabas, Iran & 7.35 & 1978 & Tabas & $\mathrm{C}$ \\
6 & Manjil, Iran & 7.37 & 1990 & Abbar & $\mathrm{E}$ \\
7 & Manjil, Iran & 7.37 & 1990 & Abhar & $\mathrm{D}$ \\
8 & Manjil, Iran & 7.37 & 1990 & Qazvin & $\mathrm{D}$ \\
9 & Manjil, Iran & 7.37 & 1990 & Rudsar & $\mathrm{D}$ \\
10 & Erzican, Turkey & 6.69 & 1992 & Erzincan & $\mathrm{D}$ \\
11 & Loma Prieta & 6.93 & 1989 & Apeel10 - Skyline & $\mathrm{E}$ \\
12 & Loma Prieta & 6.93 & 1989 & Apeel 2 - Redwood City & $\mathrm{B}$ \\
13 & Cape Mendocino & 7.01 & 1992 & Cape Mendocino & $\mathrm{C}$ \\
14 & Cape Mendocino & 7.01 & 1992 & Eureka - Myrtle \& West & $\mathrm{D}$ \\
15 & Cape Mendocino & 7.01 & 1992 & Fortuna - Fortuna Blvd & $\mathrm{D}$ \\
16 & Cape Mendocino & 7.01 & 1992 & Petrolia & $\mathrm{D}$ \\
17 & Cape Mendocino & 7.01 & 1992 & Shelter Cove Airport & $\mathrm{C}$ \\
18 & Landers & 7.28 & 1992 & Amboy & $\mathrm{D}$ \\
19 & Landers & 7.28 & 1992 & Baker Fire Station & $\mathrm{D}$ \\
20 & Landers & 7.28 & 1992 & Bell Gardens - Jaboneria & $\mathrm{C}$ \\
21 & Imperial Valley-06 & 6.53 & 1979 & Aeropuerto Mexicali" & $\mathrm{D}$ \\
22 & Imperial Valley-06 & 6.53 & 1979 & Agrarias & $\mathrm{D}$ \\
24 & Imperial Valley-06 & 6.53 & 1979 & Bonds Corner & $\mathrm{C}$ \\
24 & Imperial Valley-06 & 6.53 & 1979 & Brawley Airport & $\mathrm{D}$ \\
25 & Imperial Valley-06 & 6.53 & 1979 & Calexico Fire Station & $\mathrm{D}$ \\
26 & Imperial Valley-06 & 6.53 & 1979 & Calipatria Fire Station & $\mathrm{D}$ \\
27 & Imperial Valley-06 & 6.53 & 1979 & Cerro Prieto & $\mathrm{D}$ \\
28 & Imperial Valley-06 & 6.53 & 1979 & Chihuahua & $\mathrm{C}$ \\
29 & Imperial Valley-06 & 6.53 & 1979 & Coachella Canal \#4 \\
30 & Imperial Valley-06 & 6.53 & 1979 & Compuertas & \\
\hline & & & & & \\
& & & & & \\
\end{tabular}

3 